OPEN ACCESS

Edited by:

Joanna Mary Bridger,

Brunel University London, UK

Reviewed by:

Antonius Plagge,

University of Liverpool, UK

Michael E. Symonds,

University of Nottingham, UK

*Correspondence:

Christopher H. Eskiw

c.eskiw@usask.ca

Specialty section:

This article was submitted to Epigenomics and Epigenetics,

a section of the journal

Frontiers in Genetics

Received: 10 March 2016

Accepted: 21 July 2016

Published: 18 August 2016

Citation:

Gillespie ZE, Pickering J and Eskiw CH (2016) Better Living through Chemistry: Caloric Restriction (CR) and CR Mimetics Alter Genome

Function to Promote Increased Health and Lifespan. Front. Genet. 7:142.

doi: 10.3389/fgene.2016.00142

\section{Better Living through Chemistry: Caloric Restriction (CR) and CR Mimetics Alter Genome Function to Promote Increased Health and Lifespan}

\author{
Zoe E. Gillespie ${ }^{1}$, Joshua Pickering ${ }^{2}$ and Christopher H. Eskiw ${ }^{1,2 *}$ \\ ${ }^{1}$ Department of Food and Bioproduct Sciences, University of Saskatchewan, Saskatoon, SK, Canada, ${ }^{2}$ Department of \\ Biochemistry, University of Saskatchewan, Saskatoon, SK, Canada
}

Caloric restriction (CR), defined as decreased nutrient intake without causing malnutrition, has been documented to increase both health and lifespan across numerous organisms, including humans. Many drugs and other compounds naturally occurring in our diet (nutraceuticals) have been postulated to act as mimetics of caloric restriction, leading to a wave of research investigating the efficacy of these compounds in preventing age-related diseases and promoting healthier, longer lifespans. Although well studied at the biochemical level, there are still many unanswered questions about how CR and CR mimetics impact genome function and structure. Here we discuss how genome function and structure are influenced by CR and potential CR mimetics, including changes in gene expression profiles and epigenetic modifications and their potential to identify the genetic fountain of youth.

Keywords: caloric restriction, caloric restriction mimetics, gene expression, epigenetics/genetics, aging, cancer

\section{INTRODUCTION}

The aging process is undoubtedly the single most significant contributor to disease and death. Although this has been the inevitable outcome of all life on this planet, is aging an unavoidable consequence or can it be treated and potentially cured? As of yet this question remains unanswered, but many believe that the aging process is essentially a disease. Environmental conditions, including lifestyle, can greatly affect the rate of aging. For example, obesity or excessive ingestion of calories has been linked to increased incidents of age-related pathologies such as diabetes, cardiovascular disease, stroke, type II diabetes, and cancer development (Fontana and Klein, 2007). Several lines of research indicate that certain behaviors can increase our health and potentially lifespan, such as exercise and regimes to improve cardiovascular function. One such intervention is the use of dietary/caloric restriction (CR); the reduced intake of calories/nutrients without causing malnutrition. This was first recognized over 80 years ago in dietary restricted rats exhibiting increased mean and maximal lifespans (McCay et al., 1935). In recent years, this observation has been verified across a large number of model organisms (Longo, 2009; Lee and Longo, 2016). These observations not only demonstrated an increase in the lifespan, but also in healthspan (time spent being healthy) of these organisms coincident with a significant decrease in age-related pathologies such as cardiovascular disease, diabetes and a number of cancers. For example, when fed a diet 
consisting of $35 \%$ of the ad libitum intake but enriched with vitamins and minerals, mice lived an average of 53 months, compared to 35 months in the control ad libitum-fed group (Weindruch et al., 1986). In addition, preliminary research indicates that CR prior to chemotherapy in humans increases tumor responsiveness while reducing side effects (Lee and Longo, 2011). Several drugs or naturally occurring compounds in food (nutraceuticals) have been found to "mimic" the phenotypes of CR (Lee and Min, 2013) and could be potential alternatives to this somewhat difficult to follow dietary regime. An obvious first question: Do these compounds mirror the effects of CR? A large body of outstanding research focuses on the impact of CR and mimetics on autophagy (self-eating) in the regulation of longevity and in promoting apoptosis in cancer cells [from groups such as Drs. S. Pattingre and G. Kroemer (for an extensive review see Klionsky et al., 2008)]; however, the mechanism and impact on genome function (gene expression) and organization (epigenetic changes and physical genome folding) are less well understood. In this review, we will discuss the effect of $\mathrm{CR}$ on genome function and structure and compare the impact of CR mimetics in an attempt to gage their ability to increase health and lifespan at the genetic level.

\section{POTENTIAL IMPACT OF CR ON HOW WE AGE}

Four major theories have been proposed to explain how/why we age. These theories include; increased reactive oxygen species (ROS) and decreased DNA repair, increased circulating glucose and insulin, increased circulating growth hormone and insulinlike growth factor-1 and the hormesis hypothesis. CR has been shown to promote increased lifespan and slow the aging process (see Figure 1 for a brief summary). How does CR exhibit these effects and fit in within these proposed theories?

\section{CR REDUCES LEVELS OF REACTIVE OXYGEN SPECIES AND INCREASES DNA REPAIR}

The oxidative damage attenuation hypothesis states that increased metabolism from high levels of nutrients/calories leads to higher rates of ROS and that lowering these levels will prevent lipid, protein and DNA damage (Ray et al., 2012). Damage such as this would lead to decreased function of cellular components as well as to increased rates of mutation. However, the other side of this hypothesis states that lower metabolic rates results in decreased rates of DNA damage and increased genome stability, and thus in fewer incidents of cancer. This in itself would promote increased lifespan through improved genomic "health." Furthermore, CR resulted in a reversal of age-related DNA damage in multiple mouse tissues by inducing genes from the base excision repair (BER) pathway (Cabelofa et al., 2003) and by modifying the activity of the Ku70/80 proteins ( $\mathrm{Um}$ et al., 2003). In addition, many of the premature aging diseases, such as Werner syndrome (Sidorova, 2008) and Hutchinson Gilford Progeria syndrome (HGPS; Cao et al., 2011; Musich and Zou,
2011), have increased levels of DNA damage and lower rates of DNA repair. The rapid accumulation of DNA damage likely drives these cells into premature senescence leading to rapid onset of aging-phenotypes. Although this is logical, some data does indicate that there is not a significant enough change in free radical production upon CR to significantly decrease ROS levels (Miwa et al., 2004) indicating that the benefits of CR might not be elicited through this mechanism.

Although CR increases lifespan, it may not be due to a reduction of the ROS levels produced by mitochondria (Miwa et al., 2004), but may result from an increase in the expression of enzymes that protect against these highly reactive molecules, reducing net oxidative stress. However, in D. melanogaster exposed to CR, no link between lifespan extension and increased resistance to oxidative stress has been found. Furthermore, CR of older flies significantly decreases resistance to oxidative stress with both cytosolic superoxide dismutase 1 (SOD1) and mitochondrial SOD2 unresponsive to $\mathrm{CR}$, contrary to the proposal that CR causes life span extension by increasing resistance to oxidative stress (Kabil et al., 2007). These observations support the suggestion that CR may not elicit its beneficial properties via reduction in ROS or resistance or oxidative stress.

\section{CR DECREASES CIRCULATING GLUCOSE AND INSULIN}

The altered glucose-insulin hypothesis indicates that CR causes a decrease in the circulating levels of both insulin and glucose, leading to decreased insulin signaling. This is based on observations that decreased insulin signaling promotes increased lifespan in a variety of model organisms, including C. elegans (worms; Murphy and $\mathrm{Hu}, 2013$ ), D. melanogaster (flies; Kannan and Fridell, 2013), and M. musculus (mouse; Zhang and Liu, 2014). Increased glucose and insulin in the circulatory system will cause peripheral cells to absorb this glucose and convert it to ATP. In addition, insulin will also send positive growth and proliferative signals, pushing cellular balance toward growth and cell division. Increased metabolism will produce ROS from mitochondria as well as shortening the time in which cells repair or replace old or damaged molecules. Although enough energy is present to produce daughter cells, these rapid rates of cell division may be harmful. Therefore, CR may promote increased lifespan by decreasing rates of cell division and favoring repair and maintenance.

\section{CR DECREASES CIRCULATING GROWTH HORMONE (GH) AND INSULIN-LIKE GROWTH FACTOR-1 (IGF-1)}

The growth hormone-IGF-1 axis hypothesis states that increased signaling through these pathways advances the aging process by promoting cell growth and proliferation. Similarly to the glucose-insulin level hypothesis, CR causes the reduction of growth hormone/IGF-1 signaling (Fontana et al., 2015), favoring 


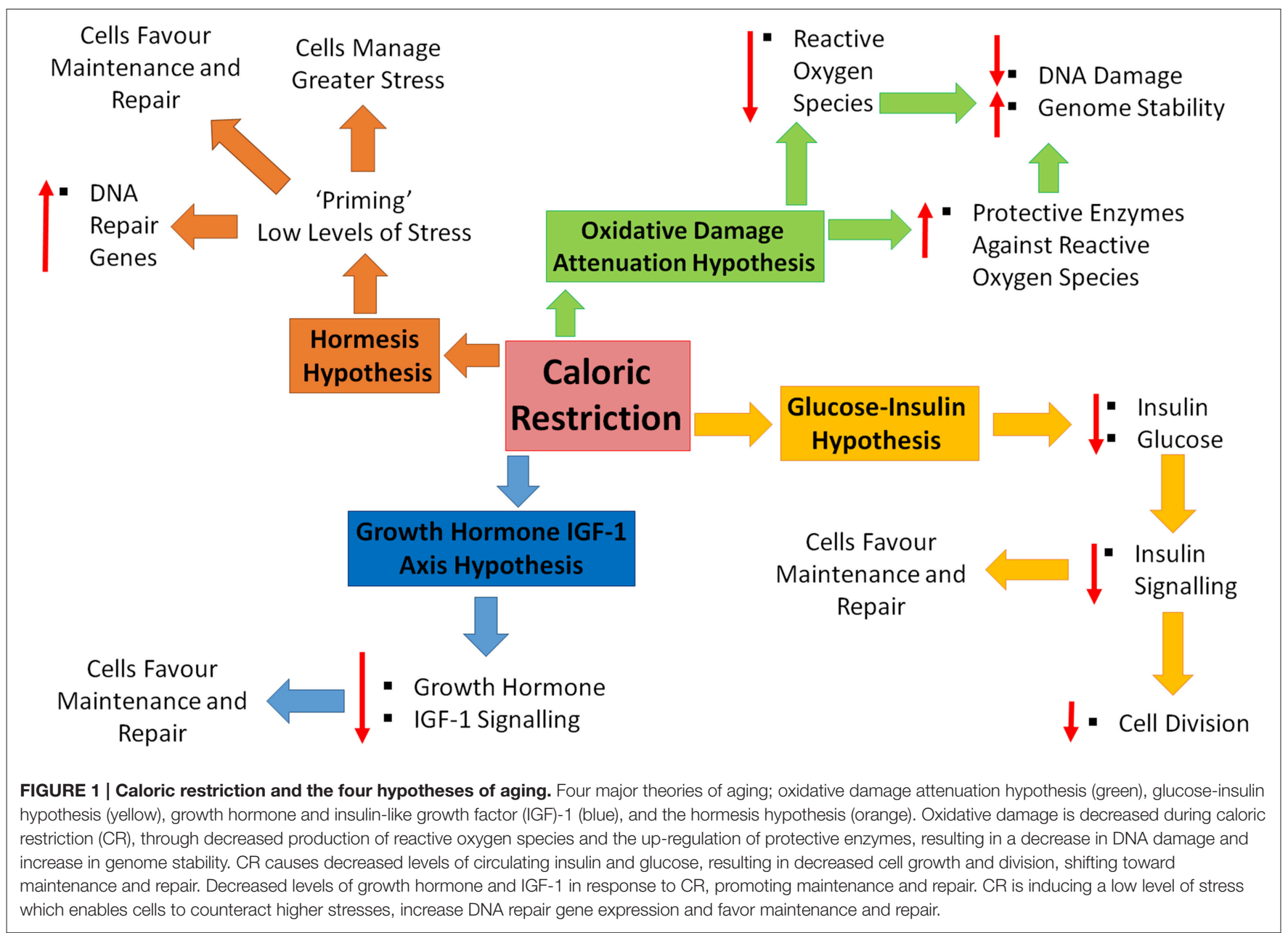

a switch from cell growth and proliferation to maintenance and repair in mice. CR phenotypes parallel long lived Ames and Snell dwarf mice, with either decreased GH receptor activity or knock-outs of the growth hormone binding protein gene exhibiting hepatic synthesis of IGF-1, reduced secretion of insulin, increased hepatic sensitivity to insulin, reduced plasma glucose, and increased resistance to oxidative stress (BrownBorg and Bartke, 2012). However, in human studies Fontana and colleagues documented that over a 2 year period of $\mathrm{CR}$, no change in circulating IGF-1 levels were observed (Fontana et al., 2008, 2015). These findings hint at two potential conclusions; (1) CR does not work in humans, only in mice, or (2) CR does not impact IGF-1 levels; however, it does impact other pathways, leading to at least increased healthspan, if not lifespan.

\section{CR ALTERS CELL BEHAVIOR FROM PROLIFERATION AND GROWTH TO MAINTENANCE AND REPAIR}

The hormesis hypothesis states that low levels or intensity of stress leads to "priming" in which cells/tissues/organs can then withstand other stresses that would normally prove terminal. It is thought that with hormesis, cells move from active growth and proliferation to a state that favors repair and maintenance. CR may prime cells by activating stress pathways to deal with later assault such as DNA damage. CR is documented to increase the expression of genes involved with DNA repair (Cabelofa et al., 2003) which will increase the efficiency at which cells are able to cope with, for example, oxidative damage. Other specific observations appear to favor this model, activating transcription factors and mechanisms controlling gene expression leading to increased levels of proteins mediating cellular stress responses (Calabrese et al., 2011).

\section{HOW ARE NUTRIENTS SENSED AT THE CELLULAR LEVEL?}

Although it is clear that CR promotes increased health and lifespan (although this is controversial in primates) several questions still remain unanswered. For example, do all cell types share common mechanisms mediating CR to promote increased cell longevity? Two major cellular energy sensors 


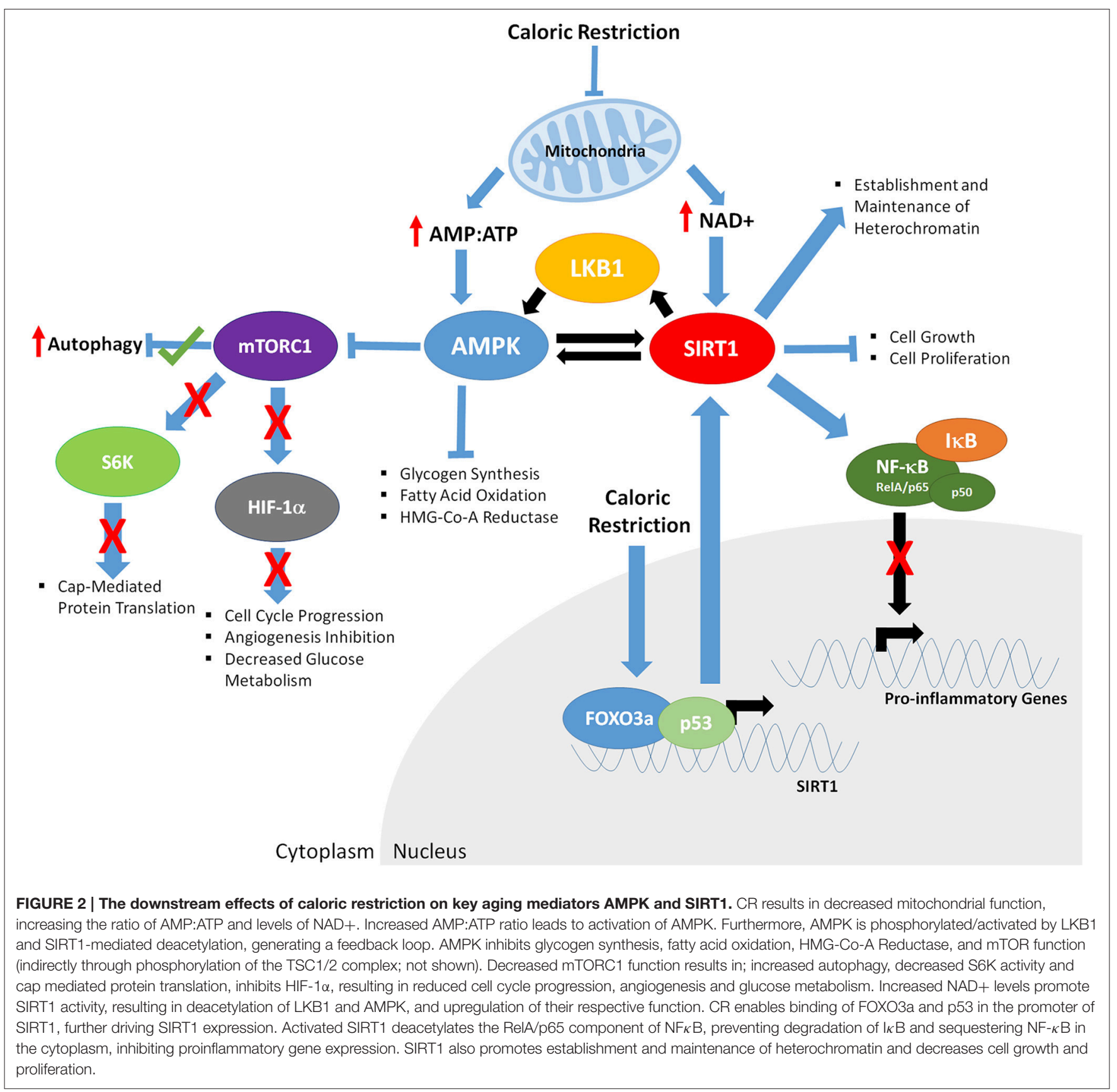

have been identified, the adenosine monophosphate kinase (AMPK) and the Sirtuin 1 (SIRT1) deacetylase (Figure 2). AMPK is activated as the ratio of cellular AMP:ATP rises, indicating low levels of energy. AMPK regulates both catabolic and anabolic processes in response to energy levels (Gowans and Hardie, 2014) and has a variety of targets. When active, AMPK inhibits glycogen synthesis, fatty acid oxidation and HMG-Co-A reductase (Lim C. T., et al., 2010). Further, it has been suggested that chronic activation of AMPK results in expression of muscle hexokinase and glucose transporters (Glut4), mimicking the effects of extensive exercise training
(Zhou et al., 2001). AMPK further activates proteins involved with fatty acid hydrolysis, glucose up-take and p53 signaling. Downstream of AMPK is the target of rapamycin (TOR) signaling cascade. TOR is evolutionarily conserved and functions in mediating growth and environmental cues; therefore, it likely plays a central role in regulating cellular responses to $\mathrm{CR}$ and CR mimetics. Comprised of two individual complexes, TORC1 and TORC2 (Yang et al., 2013), TOR further mediates signals from a variety of upstream cascades, including the insulin (Bjedov et al., 2010; Verges and Cariou, 2015) and PI3K pathways (Massacesi et al., 2016). Low cellular energy 
levels promote AMPK to phosphorylate tuberous sclerosis complex (TSC)-1 and 2 which in turn inhibit TORC1. This decrease in TORC1 function leads to decreased S6 kinase phosphorylation, leading to decreased rates of cap-mediated protein translation. AMPK has also been shown to activate and repress specific transcription factors involved with modulating gene expression. AMPK also phosphorylates SIRT1, further leading to its activation. SIRT1 is stimulated in response to decreased energy levels, leading to an increase in cellular concentration of nicotinamide adenine dinucleotide (NAD+; Lau et al., 2014). SIRT1 deacetylates both histone and nonhistone targets, in the nucleus and the cytoplasm, leading to changes in cellular function and gene expression. One of the targets of SIRT1 is the LKB1 kinase. When LKB1 is deacetylated, it phosphorylates AMPK, further driving AMPK activation. Both AMPK and SIRT1 have common targets, such as p53, implicating these proteins as central in controlling CR mediated changes in gene expression and cellular function, leading to increased health and longevity.

Parallel to AMPK, the General Control Nonderepressible (GCN2) factor detects decreased levels of amino acids through sensing of uncharged tRNAs. GCN2 decreases rates of translation, preserving limited pools of amino acids as well as conserving energy (Chantranupong et al., 2015). Furthermore, GCN2 activates the ATF4 transcription factor which then regulates the expression of genes involved with apoptosis, autophagy, and amino acid metabolism, including up-regulation of select amino acyl tRNA synthetases and amino acid transporters (Harding et al., 2000, 2003; Bunpo et al., 2010; B'Chir et al., 2013; Krokowski et al., 2013). Furthermore, Sestrin2 binds the pentameric GTPase activating TOR (GATOR) 2 complex under amino acid depleted conditions (in particular leucine), releasing GATOR1 which then bind and inhibits RAG GTPase complexes required for mTORC1 activation (Chantranupong et al., 2015). The location of both AMPK, GCN2 and Sestrin2/GATOR2, as well as many other growth factors pathways, upstream of TOR indicates that TORC1 and 2 are likely the center points mediating growth and environmental signals.

Although much is known about the cytosolic sensing of nutrients, how do these sensors link to the genome and impact gene expression? Furthermore, does the activation/inactivation of different proteins from these pathways stimulate the same sets of genes or impact the genome using common mechanisms? Are there tissue specific targets that mediate differing responses dictating how a specific cell type will react to changes in nutrient availability? When considering interfering with these pathways, does disruption at different points result in different patterns of gene expression and are these equivalent to $\mathrm{CR}$ itself? We know that signaling complexes such as TORC1 interact with a variety of transcription factors, including Hypoxia Inducible Factor $1 \alpha$ (HIFl $\alpha)$ and Peroxisome ProliferatorActivated Receptor $\gamma$ (PPAR $\gamma$ summarized by Laplante and Sabatini, 2013). We will discuss some of these factors and their impact on genome function following $\mathrm{CR}$ or in response to $\mathrm{CR}$ mimetics.

\section{WHAT ARE THE MECHANISMS DRIVING CHANGES IN GENE EXPRESSION FOLLOWING CR?}

$\mathrm{CR}$ restriction in yeast stimulates stress response transcription factors Msn2/4 and Gis1. Under normal conditions, these factors are inhibited by TOR and the yeast homolog of the S6 kinase, Sch9 (Vidan and Mitchell, 1997; Roosen et al., 2005; Swinnen et al., 2006). However, deletion of Msn2/4 and Gis1 only partially impact the $\mathrm{CR}$ stress response, indicating that other factors also mediate this reaction (Wei et al., 2008). Further, signaling to transcription factors is also indicated in Sch 9 deletion mutants which demonstrate a 10 -fold increase in lifespan (Wei et al., 2008). CR induces the function of the pyrazinamidase/nicotinamidase 1 (PNC-1) enzyme which deaminates and depletes nicotinamide (Anderson et al., 2003). Over expression of PNC-1 under normal nutrient conditions extends yeast lifespan by $70 \%$. The induction of PNC-1 was not affected by deletion of the Msn2/4 transcription factors, indicating that these factors are dispensable for PNC-1 mediated lifespan extension under conditions of decreased glucose.

One of the major factors activated under conditions of nutrient sensing is the Sirtuin (SIRT) family of deacetylase proteins that are dependent on $\mathrm{NAD}+$ which are high under conditions of nutrient deprivation (B'Chir et al., 2013). Although primarily known for their role as a histone deacetylase, SIRT proteins also target a large number of nuclear and cytosolic proteins. The extension of lifespan in yeast is linked to PNC-1 mediated deamination of nicotinamide leading to the activation of the Sir2 (yeast homolog of mammalian SIRT1) protein (Gallo et al., 2004). In mice, CR up-regulates the expression of SIRT1 (Cohen et al., 2004; Nemoto et al., 2004) while over expression of SIRT1 promotes phenotypes resembling that of CR (Bordone et al., 2007). Parallel to the increased NAD+ levels, SIRT1 is further stimulated directly by activated AMPK which deacetylates the tumor suppressor p53, inhibiting transactivation and p53-mediated gene expression (Giannakou and Partridge, 2004; Demidenko et al., 2009). SIRT1 function may be pivotal in defining how cells respond to stress induced by CR to promote longevity, whereas other stresses, such as DNA damage, lead to p53-mediated senescence or apoptosis. Somewhat paradoxically, $\operatorname{sir} 2 \Delta$ yeast mutants exhibit increased resistance to oxidative stress and heat, indicating a pro-longevity phenotype (Fabrizio et al., 2005). These findings may indicate that the impact of Sir proteins may have divergent roles in chronological (total time) vs. replicated (number of cell divisions) lifespan (Longo, 2009).

SIRT1 activation via CR also results in decreased levels of inflammation by down regulation of genes encoding cytokines (Spaulding et al., 1997; Kalani et al., 2006; Meydani et al., 2014). In macrophages, SIRT1 activation results in deacetylation of

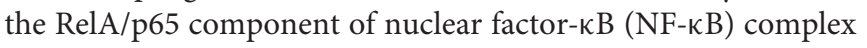
(Stein and Matter, 2011). NF- $\kappa$ B is normally sequestered in the cytoplasm by its repressor Inhibitor of $\kappa B$ (IкB). Under conditions of stress, ІКB is phosphorylated by the IK kinase (IKK) complex, leading to ІкB dissociation from NF-кB. ІкB 
is degraded and NF- $\kappa$ B translocates to the nucleus where it binds DNA and facilitates increased gene expression of proinflammatory genes. In addition, increased NF- $\kappa \mathrm{B}$ function is observed in cells from older individuals (Kriete et al., 2008; Bektas et al., 2014). Acetylation at residue lysine 310 of RelA/p65 activates NF- $\kappa \mathrm{B}$, whereas removal of this acetyl group by SIRT1 inactivates the complex resulting in decreased expression of pro-inflammatory genes (Opalach et al., 2010). CR attenuated the age-mediated effects of NF- $\kappa \mathrm{B}$, resulting in more inhibitor IкB and decreased levels of RelA/p65 in a number of model organisms (Opalach et al., 2010). Furthermore, CR caused a reduction in the constitutive activation of p65 observed in CT-2A malignant mouse astrocytoma cells, inducing apoptosis (Mulrooney et al., 2011), thus supporting the hypothesis that CR is a viable treatment strategy for patients with aggressive brain cancers (Mukherjee et al., 2004).

The forkhead family transcription factor, FOXO3a, also known as DAF-16 in C. elegans, is a key regulator of the insulin receptor (IR)/insulin-like growth factor-I signaling pathway mediated extension of lifespan. CR stimulates the hyperphosphorylation of FOXO3a leading to exclusion from the nucleus. This exclusion from the nucleus corresponded to an attenuation of Alzheimer's disease in Tg2576 mice (a specific model strain used for the study of Alzheimer's disease), indicating a link between CR, FOXO3a and age-related neurological pathologies (Qin et al., 2008). Other mammalian homologs of Daf-16 in mice; however, show signs of increased expression during $\mathrm{CR}$, indicating that these factors may be involved in promoting increased longevity in muscle cells (Furuyama et al., 2002). However, this study did not specify if these factors were prevented from becoming nuclear, indicating that there may be a cytosolic role for FOXOs, facilitating autophagy and extending lifespan. In addition, SIRT2 deacetylates FOXO3a in mice (Brunet et al., 2004; Daitoku et al., 2004; van der Horst et al., 2004), resulting in increased DNA binding of FOXO3a and expression of FOXO target genes, p27-Kip1, manganese superoxide dismutase (Kops et al., 2002), catalase (Furuyama et al., 2000; Nemoto and Finkel, 2002), and under conditions of severe stress, deacetylates and activates the pro-apoptotic protein Bim/BCL2L11 (Wang et al., 2012). In addition to these genes, FOXO3a also targets a variety of genes involved in several processes, including G1 arrest, G2 delay, DNA repair, ROS response, and glucose metabolism. Expression of SIRT1 is also dependent on the physical interaction of FOXO3a with p53 to promote binding within the SIRT1 promoter under conditions of decreased nutrient availability (Nemoto et al., 2004). In a separate experiment, knockout of FOXO3a in mice demonstrated that they no longer benefit from CR, indicating that this transcription factor is central in regulating genes that promote increased health and lifespan (Shimokawa et al., 2015), possibly mediating the interaction and functions of SIRT1 and p53. These observations strongly link SIRT1, p53, and FOXO3a in mediating a stress response in cells that favors a decrease in cell growth and proliferation without resulting in cell death.

Members of the PPAR nuclear receptor family PPAR $\alpha$, $\operatorname{PPAR} \beta / \delta$, and PPAR $\gamma$ are involved with regulating insulin sensitivity, adipogenesis, lipid metabolism, and blood pressure
(Brown and Plutzky, 2007). Numerous polymorphisms have been identified in the PPAR genes that are directly related to type II diabetes and metabolic syndrome, indicating the pivotal role of these receptors in regulating gene expression in response to diet. PPAR $\gamma$ directly interacts with SITR1 under normal conditions. Diets which promote the formation of advanced glycation end products (AGEs) in diabetic patients and older individuals causes a decrease in both of these proteins (Singh et al., 2014). This decrease in PPAR $\gamma$ and SIRT1 further corresponds to an increase in inflammation. Restricting the dietary intake of AGEs in combination with CR re-established SIRT1 and PPAR $\gamma$ expression, decreasing the inflammatory response (Uribarri et al., 2015). CR as a treatment for disease represents a specific challenge when considering PPAR members. Although CR reduces the activity of PPARs through decreased activation, this leads to a decrease in the expression of genes regulating fatty acid metabolism. This results in the build-up of fatty acids in the liver causing steatosis/fatty liver disease. Paradoxically, Oshida and colleagues report that triglycerides directly activate PPAR $\alpha$ during fasting or CR, both leading to cell proliferation and inhibition of inflammation (Oshida et al., 2015), demonstrating that both indirect and direct mechanisms control PPAR function.

CR decreases the expression of HIF- $1 \alpha$-mediated genes (Chen et al., 2009). HIF-1 $\alpha$ activity is associated with a variety of other physiological stimuli such as heat acclimation, acidosis, nitric oxide exposure, inflammation and oxidative stress (Reviewed by Kang et al., 2005). In addition, HIF- $1 \alpha$ activity is increased in aged rats, up-regulating genes such as heme oxygenase-1 (HO-1), vascular endothelial growth factor (VEGF), erythropoietin (EPO), and inducible nitric oxide synthase (iNOS; Kang et al., 2005), with CR demonstrated to decrease the expression of these genes. CR may facilitate this process through the inhibition of mTOR signaling and decreased protein translation. Several studies have demonstrated that HIF-1 $\alpha$ translation is dependent on mTOR activity (Bernardi et al., 2006; Hui et al., 2006). Repression of HIF$1 \alpha$, therefore, leads to decreased levels of several genes including those regulating cell cycle progression, angiogenesis, and glucose metabolism (reviewed in Hong et al., 2004). In addition, SIRT1 (which is up-regulated under conditions of CR) deacetylates HIF1 $\alpha$ preventing recruitment of the acetyl transferase p300 and further inactivation of HIF- $1 \alpha$ target genes (Lim J. H., et al., 2010). HIF-1 $\alpha$ also interacts with the redox factor REF1 , which is also involved with NF- $\kappa \mathrm{B}$ signaling, indicating that both HIF- $1 \alpha$ and NF- $\kappa$ B may respond in parallel under nutrientrich conditions. Therefore, the repression of both the NF- $\kappa \mathrm{B}$ and HIF- $1 \alpha$ responses by CR may be analogous reactions to prevent inflammatory or stress responses that could potentially lead to carcinogenesis.

\section{GENOME WIDE IMPACT OF CR ON GENE EXPRESSION/GENE PATHWAYS}

A large number of gene expression studies have been performed in order to determine the impact of CR on genome function. $\mathrm{CR}$ is well known to elicit a change in cell behavior marked by 
a decrease in cell proliferation and shift to cellular maintenance and repair. Changes in phenotype are accompanied by changes in gene expression; therefore, what impact does CR have on gene expression from across the genome? CR of yeast caused 646 genes to significantly change expression leading to lifespan extension (Choi et al., 2013). These genes were identified to be positively correlated with transcriptional regulation, ribosomal processing and genome stability and negatively correlated with pathways involved with metabolism or cell cycle progression. Analysis of these genes indicated that the transcription factors Azoospermia Factor 1 (AZF1), Heatshock Factor 1 (HSF1), and X-box binding protein (XBP1) were involved with mediating lifespan extension under conditions of CR due to decreased glucose levels (Choi et al., 2013). These factors are involved with regulating stress response, indicating that $\mathrm{CR}$ may function as a cellular stress which promotes hormesis in yeast.

Whitaker and colleagues demonstrate that the timing of the gene expression analysis is critical in determining which genes are central in mediating increased longevity in response to CR (Whitaker et al., 2014). It was suggested that a small number of genes will rapidly be induced while secondary effects from initial changes would be observed at later time points. In this study, 853 genes were identified that changed expression over a 40 day period in D. melanogaster. Genes that changed expression demonstrated enrichment in pathways associated with folate biosynthesis, ubiquinone/terpenoid-quinone biosynthesis, and oxidative phosphorylation (Whitaker et al., 2014). Of these genes, very few were in common with starvation. Those that were common appeared to change expression in the opposite direction indicating that the response to $\mathrm{CR}$ is divergent from extreme nutrient deprivation (Whitaker et al., 2014). In support of this, starvation of $D$. melanogaster larvae exhibited differential activation of specific genes (Zinke et al., 2002) indicating that different levels of nutrients or duration may also impact expression profiles.

In an another meta-analyses, Swindell and colleagues identified more than 10,000 differentially expressed genes from over 40 independent datasets (Swindell, 2009). A metaanalyses of gene expression profiles in mammalian systems demonstrated that $\mathrm{CR}$ resulted in gene expression changes involved with a number of biological pathways, including growth hormone signaling, lipid metabolism, immune response, retinol metabolism, copper ion detoxification, and circadian rhythms (Whitaker et al., 2014). The large number of genes observed to have changed expression is likely due to many factors, including the use of expression data from different species, tissues and time points as well as also identifying secondary effects. It is more likely that in response to $\mathrm{CR}$ a few genes will have altered expression which leads to changes in cellular function and other secondary effects.

The identification of CR influencing circadian rhythm pathways (Swindell, 2009) and genes related to circadian rhythms is intriguing, demonstrating that diet can also affect sleep patterns, further impacting health. H3K4me3 deposited by the Mixed-lineage Leukemia 1 (MLL1) methyltransferase regulates the binding of the core transcription factors, circadian locomotor output cycles kaput (CLOCK) and BMAL1, controlling the cyclic expression of clock-controlled genes (CCGs). Indeed, the link between diet and circadian rhythms is likely mediated through SIRT1 function, with NAD+ levels influencing the epigenetic modification and expression CCGs therefore impacting biological rhythms (Aguilar-Arnal et al., 2015). Furthermore, AMPK phosphorylates the cryptochrome protein, resulting in the inhibition of CLOCK-mediated CCG expression (Masri and Sassone-Corsi, 2013). This provides further evidence for levels of cellular energy being essential in regulating health promoting biological processes such as circadian rhythms.

Contrary to the finding of Swindell and colleagues, another meta-analysis of microarray datasets from mouse, rats and pigs measuring gene expression changes as a result of $\mathrm{CR}$ demonstrated that only a handful of genes (101 up-regulated and 73 down-regulated) across multiple experiments. The Gene Ontology (GO) terms for these genes demonstrated enrichment in processes related to lipid metabolism and AcetylCoA reductase activity (Plank et al., 2012). In addition, terms for processes related to circadian rhythms were also identified in over expressed genes while down regulated genes showed enrichment for GO terms related to steroid biosynthesis, reduced transcription of genes involved with sterol biosynthesis and innate immune-response. However, the low number of genes identified over meta-analyses may reflect the heterogeneity created by using cross species comparisons and more candidates involved with CR may have been overlooked. Microarray analysis of multiple mouse tissues also indicated that there are tissue specific changes in gene expression related to CR (Park and Prolla, 2005). In an additional study of gene expression of muscle from male mice (Weindruch et al., 2001), microarray analysis demonstrated that only 58 genes were up-regulated and 55 genes were down-regulated. Of the 58 up-regulated genes, $16 \%$ were related to stress response and coincided with an increase in ROS produced in older mice. Many of these genes were either completely or partially repressed in CR mice fed $76 \%$ of the calories of mice on control diets. CR itself induced the expression of 51 genes, many of which were related to energy metabolism. Furthermore, CR increased the expression of genes involved with detoxification, which are hypothesized to decrease normally with age (Fu and Klaassen, 2014). An examination of 98 xenobiotic processing genes not only demonstrated an increase in expression of these genes, but also that CR favored the expression of female pre-dominantly expressed genes over predominantly male expressed detoxification genes in the livers of male mice. These findings indicate that the CR may be inducing a shift toward maintenance and repair and re-establishing the expression of genes involved with detoxification, supporting the hormesis model.

Despite this plethora of publications regarding the impact of $\mathrm{CR}$ on genome function, there appears to be little consensus as to the genes that are responsible for promoting increased health and lifespan. This may be due to the complexity of the responses and differing mechanisms not only between cell types within the same organisms but also differing response between systems. Furthermore, the observation by Whitaker and colleagues indicating that the timing of analysis will be pivotal 
(Whitaker et al., 2014) highlighting the challenges underling the identification of genes controlling CR mediated impacts on health and lifespan. We will also note at this point that there is still controversy surrounding the impact of CR on longevity. For example, Harper et al. (2006) suggest that CR has no significant impact on mice outside of the laboratory setting. One explanation for this is that the CR regimes imposed by laboratories is too strict when compared to wild mice. Furthermore, wild mice also have more complex genetic backgrounds and diversity in their populations. To further complicate these issues, Mattison et al. (2012) indicated no impact on the survival of young or old rhesus monkeys exposed to CR. Regardless, both mice and rhesus monkeys did demonstrate an increase in healthspan and fewer age-associated pathologies in response to CR, arguing that although a statistical significance in lifespan is debatable, the evidence supporting a positive impact on health is strong. The complexities of these analyses may indicate that each cell/tissue type may have different genes that are active or inactivated as a result of CR.

\section{EPIGENETIC CHANGES IN RESPONSE TO CR}

Critical to this discussion is the subject of epigenetics. Although the primary sequence of the genome is of obvious importance, with mutations in critical genes either promoting or shortening health and lifespan, it is not the only consideration when contemplating the impact of CR or CR mimetics. During the aging process our epigenome, the collection of epigenetic marks including histone modifications and $\mathrm{CpG}$ island methylation, is altered. For example, there is a genome-wide loss of histone 3 lysine 27 trimethylation (H3K27me3) and CpG island methylation resulting in the reactivation of repressed genes. This represents a loss of gene regulation, thus promoting cancer development (Issa et al., 1994, 2001; Knapowski et al., 2002). In prematurely aging HGPS cells, there is a distinct lack of heterochromatin with genome-wide loss of gene regulation (Kubben et al., 2012). Paradoxically, there are some CpG islands near promoters that become hypermethylated during aging (Singhal et al., 1987; Johnson et al., 2012), which results in the repression of nearby genes. Although the accumulation of mutations over time will impact genome function, another major driver of cellular aging is the loss of repressive epigenetic marks. These changes in epigenetic marks lead to changes in gene expression profiles, therefore, it is important to consider how CR impacts methylation and epigenetic marks across the genome.

Calories and nutrients from our diet are one of the most reliable, efficient and profound environmental factors leading to alteration in health and lifespan (Weindruch et al., 1986; Sinclair, 2005). CR is able to mediate specific changes in gene methylation profiles. For example, hypermethylation of the $c-m y c$ oncogene was observed in mice exposed to CR (Miyamura et al., 1993), which also lead to hypermethylation of the ras oncogene in rat pancreatic cells (Haas et al., 1993). These observations indicate that diet and cellular energy levels impact some of the most well characterized regulators of cancer and that this link is not a new phenomenon. Furthermore, the diets of our parents will play a large role in the profiles of our genomic function regardless of mutations within genes. A strong piece of evidence supporting the importance of epigenetics is the study from the Kim group; genome-wide sequencing of super-centenarians (110 years or older) demonstrated no significant enrichment for any single rare genetic variant to explain this longevity as compared to control genomes (Gierman et al., 2014). It is, therefore, likely that epigenetic modification to either histones or $\mathrm{CpG}$ islands due to environmental or maternal influences are responsible. In addition, CR prior to or during pregnancy can greatly impact the health and life span of offspring. CR of parents either prior to or during pregnancy has also shown to have benefits in the offspring, further supporting the role of epigenetics in regulating and increasing lifespan. Transgenerational epigenetic inheritance (the impact of environment on epigenetic status that is then passed to offspring) has been described in a diverse range of organisms ranging from plants to mammals. In $C$. elegans, knockdown of chromatin modifiers related to H3K4me3 in the F0 generation showed increased lifespan of offspring in the F3 generation, indicating a role for epigenetics in controlling inherited longevity (Greer et al., 2011). However, this does not appear to be the case with CR. In mice, CR prior to (1 month before pregnancy) or during pre-pregnancy leads to decreased health in offspring two generations later (Ponzio et al., 2012; Palou et al., 2015). CR of non-human primates during pregnancy also impacts the development of kidneys in the offspring, leading to decrease numbers of glomeruli (Nijland et al., 2007). This change in kidney development also corresponded to changes in gene expression from a number of different pathways, including the up-regulation of steroid metabolism and mTOR genes, and down-regulation of genes associated with oxidative phosphorylation, amino acid metabolism and cytokine-cytokine receptor interactions (Nijland et al., 2007). Therefore, despite not always having a positive impact, it is clear that CR, as well as other environmental factors experienced by the parents, has transgenerational epigenetic impact on the offspring influencing health and lifespan.

SIRT1 may also play a role in the establishment and maintenance of heterochromatin as a function of aging and CR. Endogenous SIRT1 can mediate the deacetylation of H4K16 and $\mathrm{H} 3 \mathrm{~K} 9$ leading to increased levels of $\mathrm{H} 3 \mathrm{~K} 9 \mathrm{me}$, histone $\mathrm{H} 1$ recruitment, facilitating heterochromatin formation (Vaquero et al., 2004). This links SIRT1 deacetylase function not only with the regulation of specific factors and decreased gene expression but also to repression of specific loci and heterochromatin maintenance. This link is strengthened through the observation SIRT1 deacetylates and activates SUV39H1 methyltransferase (Vaquero et al., 2004, 2007) responsible for the deposition on methyl marks on H3K9 residues. This indicates that SIRT1 activity during $\mathrm{CR}$ is key in maintaining gene expression profiles through the deacetylation of genomic regions as well as the modulation of other proteins involved with chromatin structure.

What are some of the specific loci that are regulated by changes in epigenetic status in response to CR? In normal lung fibroblasts (WI-38) deprived of glucose, there is a marked change in epigenetic status with $p 16$-ink promoter regions becoming less 
acetylated and hypermethylated. This change in acetylation and methylation causes p16-ink inactivation in leading to decreased cell proliferation (Li et al., 2010a). Contrary to this, the human Telomerase (hTERT) gene which encodes the main catalytic subunit of the telomerase enzyme, was activated becoming more acetylated and hypomethylated (Li et al., 2010a). These effects were opposite in immortalized cells, demonstrating a significant reduction in methylation with the p16-ink promoter and an increase in acetylation. The hTERT promoter became enriched for $\mathrm{H} 3 \mathrm{~K} 9 \mathrm{me} 3$ and deacetylated in response to glucose withdrawal. The introduction of 5-aza-cytosine or trichsostatin A (TSA) reversed these effects, indicating that there is an epigenetic response of these promoters to glucose deprivation. Glucose deprivation (CR) promoted cell cycle arrest in normal fibroblasts while causing apoptosis in immortalized cells, demonstrating that glucose deprivation promotes maintenance and repair in normal cells while forcing cancerous cells to undergo apoptosis due to a lack of energy (Li et al., 2010a).

\section{ARE COMPOUNDS THAT HAVE LIFESPAN EXTENSION PROPERTIES FUNCTIONING THROUGH SIMILAR PATHWAYS TO CR?}

Cellular nutrient sensing is complex, with multiple proteins from several signaling cascades becoming active or repressed in response to changes in the levels of nutrients such as glucose, amino acids, hormones and cellular energy. Several pharmacological agents and naturally occurring nutricueticals can interact/inhibit/disrupt many of these proteins (Figure 3), disrupting the ability of cellular nutrient sensing. But do these compounds truly mimic CR?

\section{RAPAMYCIN}

In all model organisms tested thus far, caloric restriction has been shown to significantly down regulate mTOR function leading to increased autophagy and decreased protein translation (Blagosklonny, 2010). However, there are compounds that are hypothesized to mimic the effects of caloric restriction by disrupting a cells ability to sense nutrients in their environment. This is achieved as a result of mTOR inhibition, either directly or via activation/inhibition of factors up-stream or down-stream of mTOR complexes. The most well-known and characterized of these inhibitors is rapamycin. Rapamycin, a macrocyclic lactone-based compound, was first derived from the bacterium Streptomyces hygroscopicus found in the soil of Easter Island (Sehgal et al., 1975). Since its isolation, rapamycin has become extensively used as an immunosuppressant following organ transplantation (Dumont and Su, 1996). Rapamycin acts primarily through the TOR pathway; in mammals, rapamycin is bound between FKBP12 and the mTOR kinase subunits of mTORC1, causing functional inhibition of mTOR and the mTOR pathway (Dumont and Su, 1996). The downstream effects of this inhibition include a decrease in cap-mediated protein translation (Richter and Sonenberg, 2005) and an increase in autophagy (Jung et al., 2010), both associated with promoting health and lifespan. Rapamycin has been documented to ameliorate age related-disease phenotypes of numerous cell-based models (cancer; Shapira et al., 2006; Fang et al., 2011; Suzuki et al., 2011), cardiovascular disease (Das et al., 2014), the premature aging disease HGPS (Cao et al., 2011), neurodegenerative diseases (Santos et al., 2011) and extend lifespan in numerous model organisms including S. cerevisiae (Powers et al., 2006), D. melanogaster (Bjedov et al., 2010), and M. muscularis (Miller et al., 2011, 2014; Zhang et al., 2014).

The accumulation of cells in senescence has been extensively linked to aging and the aging phenotype (Kong et al., 2011), with clearance of senescent cells documented to improve the symptoms of age-associated diseases (Baker et al., 2011). Mesangial cells (MC) became senescent in response to high glucose, increasing mTOR expression and decreasing SIRT1 expression (Zhang et al., 2012). It was demonstrated that rapamycin interfered with MC senescence coincident with increased SIRT1 expression (Zhang et al., 2012). In macrophages, inhibition of SIRT1 resulted in over expression of inflammationrelated genes (TNF- $\alpha, I L-6)$ through NF- $\kappa$ B signaling activation. Rapamycin ameliorated SIRT1 inhibition, reducing NF- $\kappa$ B mediated inflammation (Takeda-Watanabe et al., 2012). The senescence associated secretory phenotype (SASP) involves secretion of pro-inflammatory cytokines from senescent cells into the local tissues environment, causing deleterious effects to surrounding cells and contributing to the aging process (Coppe et al., 2010). It is possible that SIRT1 is essential in regulating inflammation during the aging process, reducing inflammationlinked signaling in response to rapamycin treatment and promoting health and longevity. Similar evidence is present in response to CR (Spaulding et al., 1997; Kalani et al., 2006; Meydani et al., 2014).

Rapamycin has been extensively linked to cytokine expression and regulation across multiple cell lines. In healthy human foreskin fibroblasts [2DD], rapamycin caused up-regulation of numerous genes, including cytokine genes from the IL6 signaling cascade, such as IL-6, IL-8, IL-11, and leukemia inhibitory factor (LIF; Gillespie et al., 2015). Analysis of Kyoto Encyclopedia of Genes and Genomes (KEGG) pathway terms identified a specific enrichment of cytokine-cytokine receptor interactions. Furthermore, transcription factor motif searches of up-regulated promoters and subsequent chromatin immunoprecipitation (ChIP) analyses demonstrated STAT5A/B as likely mediating rapamycin-induced changes in gene expression (Gillespie et al., 2015). Compounds that activate SIRT1 function suppress pSTAT5A/B signaling in response to $I L-2$ and decrease mouse and human T-cell proliferation (Gardner et al., 2013). In orbital fibroblasts, rapamycin increased TNF $\alpha$ induced IL- 6 and IL-8 secretion by suppressing programmed cell death 4 (PDCD4) degradation (Lee et al., 2013), further increasing TNF, IL-6 and decreasing IL-10 levels in human macrophages. Contrary to this, in human oral keratinocytes (Su et al., 2015), rapamycin suppresses TLR3 and subsequent NF- $\mathrm{B}$ signaling, inhibiting the production of interleukin-1 beta (IL-1 $\beta, T N F \alpha$, and IFN$\beta$; but enhancing $I L-12 p 70$ production (Zhao et al., 2010). Another study in senescent fibroblasts treated with rapamycin similarly demonstrated a decrease in $I L-6 /$ cytokine production, 


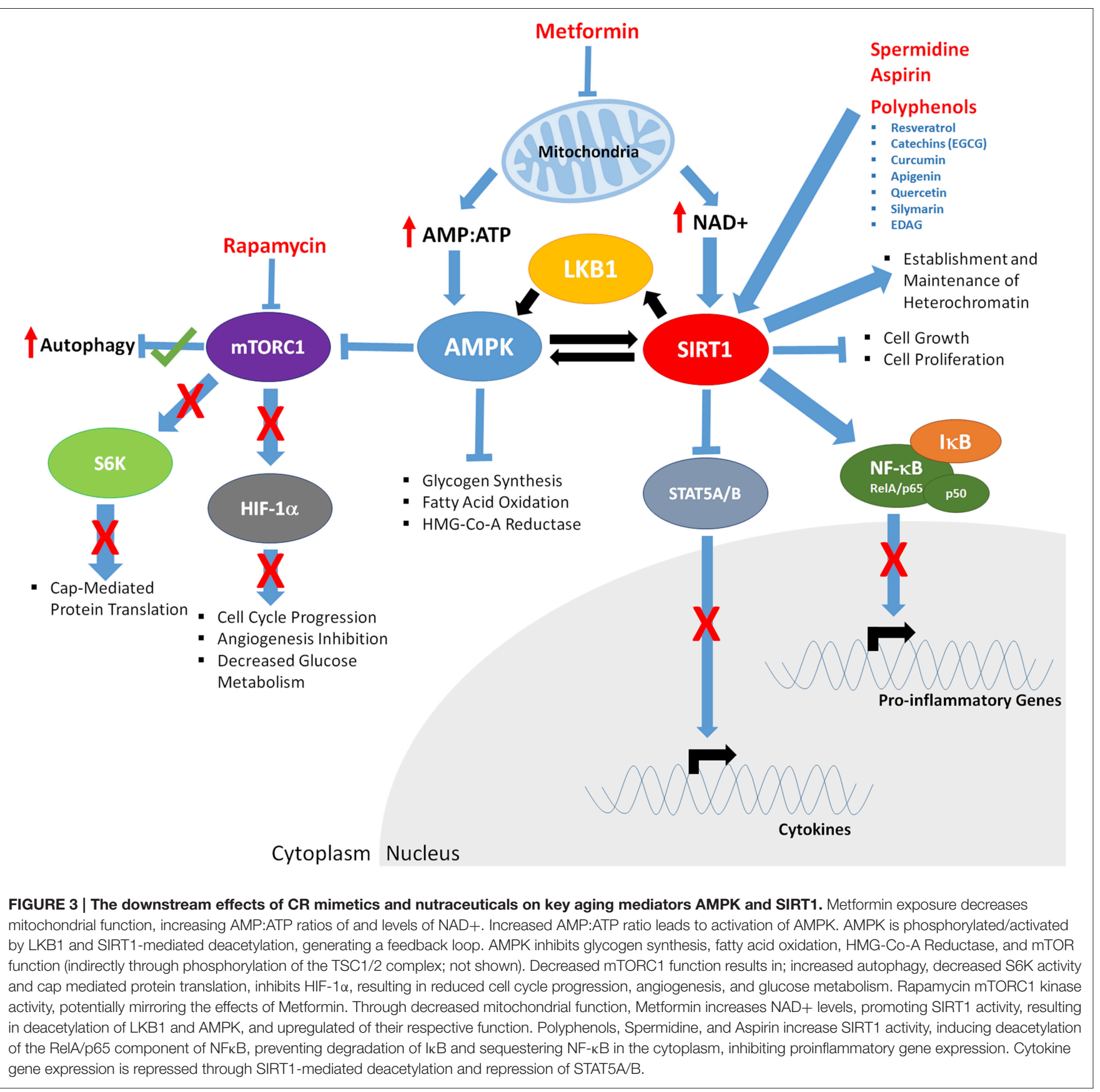

selectively suppressing translation of IL-1A (Laberge et al., 2015). These findings provide further evidence of SASP and the impact rapamycin may have on SASP to promote health and lifespan in cells. The conflicting impact of rapamycin on repressing or promoting gene expression/cytokine production may be complex and influenced by cell type and cells state (proliferative vs. senescent) in addition to the concentration and length of time in which cells have been exposed.

As with CR, rapamycin could have the opposite effect on cancer cells, resulting in cell death instead of promoting increased maintenance and repair. In oral squamous cell carcinoma (OSCC) Tca8113 and breast cancer cell lines, rapamycin down-regulated expression of S-phase kinase associated protein2 (SKP2) and increased FOXO3a protein stability. When combined with cisplatin, rapamycin induced the up-regulation of feedback AKT activation-mediated FOXO3a phosphorylation leading to accumulation of p27 and Bim, increasing apoptosis (Shapira et al., 2006; Fang et al., 2011). The effects of rapamycin on these cancerous cells is parallel to the impact of CR inducing apoptosis previously identified. In healthy human cells, the apoptosis-promoting properties of FOXO are attenuated by SIRT1, further linking involvement of FOXO inhibition and SIRT1 deacetylase activity in moving cells away from cell death and toward survival (Giannakou and Partridge, 2004) in response 
to treatment with rapamycin and other longevity promoting compounds.

Reports have linked CR with mTOR signaling, resulting in increased expression of genes encoding proteins that protect against oxidative damage. It is possible that rapamycin treatment may induce similar effects. TOR function is associated with decreased transcription of stress response genes in S. cerevisiae via a mechanism involving Tap42 and the transcription factor Msn2 (Vidan and Mitchell, 1997; Roosen et al., 2005; Swinnen et al., 2006). Upon examination of rapamycin-treated mice spermatogonial stem cells (SSC), oxidative stress response genes were up-regulated (SOD1, glutathione reductase, $\delta$-aminolevulinate dehydratase; Kofman et al., 2012). In older, wild-type mice, the expression of these genes was reduced. It is possible to conclude that oxidative stress genes are induced in response to rapamycin and may promote cellular longevity in SSC cells from mice (Kofman et al., 2012), possibly priming cells to manage alternative stresses, parallel to CR-mediated hormesis. Pre-treatment of lung carcinoma cells (A549) with rapamycin inhibited ROS and suppressed ROS-dependent apoptosis (Suzuki et al., 2011). In human corneal endothelial cells, rapamycin prevents cell-death as a result of oxidative injury via inhibition of ROS production (Shin et al., 2011) and although not directly reported, this was likely due to increased expression of genes encoding oxidative damage proteins. Although this links rapamycin to increasing health and lifespan, this link is divergent to that observed in CR. CR may improve health/lifespan by influencing protective enzymes, whilst rapamycin appears to inhibit ROS production and induce oxidative response genes.

Some controversy exists over the extent to which rapamycin impacts genome function in terms of gene expression. In healthy human fibroblasts treated with rapamycin for 5 days, 537 genes were identified by RNA sequencing with greater than five-fold change in expression (Gillespie et al., 2015); however, in the epididymal white adipose tissue of mice treated with rapamycin for 6 months, just 6 down-regulated genes were identified (Fok et al., 2014). This further supports the idea that rapamycin induces species/cell-type specific responses. It could also indicate that response to rapamycin is time specific, or even that the lack of genes significantly altered by long-term rapamycin treatment is the result of cells acclimatizing to long-term exposure. This is further supported through studies that document chronic exposure to rapamycin inducing inhibition of TORC2 under the same concentrations that only activate TORC1 under short-term exposure (Sarbassov et al., 2006).

Genome organization is tightly linked to genome function which not only includes interactions between specific genes/regulatory elements (Tolhuis et al., 2002; Schoenfelder et al., 2010; Zhou et al., 2014) but also the re-positioning of chromosome territories within the nuclear volume of cells. Chromosome territories rapidly re-locate in dermal fibroblasts in response to both quiescence induction via reduced serum and as cells become senescent (Mehta et al., 2010, 2011). The dynamic and rapid nature of this reorganization demonstrates the responsiveness of the genome to external stimuli. In the premature aging disease HGPS, treatment with rapamycin resulted in chromosomes re-positioning to a similar state to that of healthy cells, coincident with an improvement in disease phenotype (Cao et al., 2011). Furthermore, in healthy human fibroblasts, rapamycin induced repositioning of chromosomes 10 and 18 toward a more quiescent-like organization in parallel with an increase in population doubling times (Gillespie et al., 2015). The rapamycin-induced re-positioning of chromosomes was coincident with a significant change in gene expression. These findings link rapamycin-mediated inhibition of mTOR, chromosome territory positioning and gene expression profiles with the rate of cell growth. Furthermore, cells from HGPS patients lack heterochromatin and exhibited decreased DNA repair kinetics. This HGPS-associated loss of heterochromatin is parallel, although accelerated, to that occurring in normal aged cells. Cao and colleagues demonstrated that rapamycin restored heterochromatin domains in HGPS cells and DNA repair kinetics following the autophagy mediated degradation of the cytotoxic Progerin protein (Musich and Zou, 2011). This restoration of heterochromatin and DNA repair resulted in increased cellular lifespan. It is likely that changes in genome organization and the maintenance of heterochromatin will be observed under conditions of CR or as a result of CR mimetics that force changes in gene expression.

\section{POLYPHENOLS}

Polyphenols are portrayed as nutraceuticals in the media for their ability to act as free radical scavengers. This scavenging ability is due to the aromatic rings that are able to distribute charge over the molecule. It is theorized that ingested polyphenols are bioavailable in cells resulting in decreased metabolic ROS byproducts, reducing damage to molecules such as DNA. This scavenging ability is far from the only health promoting properties these molecules have. There are a number of naturally occurring polyphenols, including curcumin (Jobin et al., 1999), apigenin (Wang et al., 2014), quercetin (Endale et al., 2013), silymarin (Saliou et al., 1998), and (my favorite) $2 \alpha, 5$-epoxy-5,10-dihydroxy-6 $\alpha$-angeloyloxy-9 $\beta$-(3methylbutyloxy)-germacran-8 $\alpha, 12$-olide (EDAG; Lee et al., 2011) that function to inhibit inflammation. Under conditions that induce inflammation, such as lipopolysaccharide treatment, NF$\kappa \mathrm{B}$ is released from its inhibitor I $\mathrm{B}$, translocates to the nucleus and promotes pro-inflammatory transcription. Collectively these polyphenolic compounds prevent the degradation of $І \kappa \mathrm{B}$, blocking NF- $\kappa \mathrm{B}$ function and the inflammatory response. A comprehensive examination of the impact of several polyphenols on NF- $\mathrm{B}$ signaling demonstrated, however, that differing conditions or cell types, such as intestinal Coca-2 cells, may have opposite effects (Romier et al., 2008).

\section{RESVERATROL}

Resveratrol (3,5, $4^{\prime}$-trihydroxystilbene), is a well-known polyphenol commonly found in a variety of foods, including a number of berries, peanuts, grapes and red wine (Stervbo et al., 2007). In fact, the presence of resveratrol in red wine has been linked to the decreased levels of cardiovascular disease in 
the French population (Renaud and de Lorgeril, 1992). It has since been documented that resveratrol has beneficial effects on cancer, including the prevention of carcinogenesis in mice, and the reduction in proliferation in a number of cancer-based cell lines (prostate; Narayanan et al., 2003; Jones et al., 2005, ovarian; Yang et al., 2003, breast; Chin et al., 2014). Given that both cancer and cardiovascular disease are considered as age-related diseases, the consideration of resveratrol as a potential intervention for age-related diseases is realistic, with evidence already implicating resveratrol as beneficial across numerous areas of aging (e.g., cognitive aging in mice; Torres-Perez et al., 2015). Although it has been suggested that resveratrol has no impact on lifespan (Bass et al., 2007), several studies have reported lifespan extension across a number of model organisms, such as $N$. furzeri (a short-lived seasonal fish; Valenzano et al., 2006), S. cerevisiae (Howitz et al., 2003), C. elegans, and D. melanogaster (Wood et al., 2004). The mechanisms for this resveratrol associated lifespan extension are thought to be centered around activation of Sirtuin deacetylases (whether this activation be direct or indirect; Pacholec et al., 2010), which are linked to CR-mediated lifespan extension.

Resveratrol may also promote increased health by altering gene expression patterns. In the prostate cancer cell line, LNCaP, 1656 transcripts were identified as changing greater than two fold expression in response to resveratrol treatment, $37 \%$ up-regulated and 63\% down-regulated (Jones et al., 2005). This change in transcript profile was coincident with a decrease in cell proliferation. Multiple labs have demonstrated that resveratrol impacts both the androgen (Narayanan et al., 2003; Jones et al., 2005; Wang et al., 2008) and estrogen (Gehm et al., 1997; Wang et al., 2008) receptor pathways. Androgens mediate development and physiological responses and have been associated with cellular functions such as cell cycle regulation, transcription, cell proliferation and differentiation, including down-regulation of prostate specific antigen (PSA; Jones et al., 2005; Wang et al., 2008) and $A R$ and the AR co-activator $A R A$ (Narayanan et al., 2003; Jones et al., 2005). Resveratrol may be altering expression of genes via inhibition of androgen and estrogen receptor-dependent signaling pathways (Wang et al., 2008). Resveratrol, via activation of FOXO transcription factors, induces growth arrest and apoptosis in LNCaP, with in vitro experiments inducing decreased tumor apoptosis and increased tumor angiogenesis despite initially delaying tumor growth (Wang et al., 2008; Chen et al., 2010). These observations, as well as others, demonstrate that resveratrol induces gene expression profiles that promote cell death in a number of cancer cell lines (Hsieh et al., 1999; Young et al., 2005; Chin et al., 2014). SIRT1 has been identified to deacetylate both the androgen (Fu et al., 2006) and estrogen (Yao et al., 2010) receptors in addition to FOXO proteins [notably resveratrol treatment induces expression of FOXO transcription factors, with SIRT1/FOXO demonstrated to be responsible for increased endothelial NO synthase (eNOS) which increases nitric oxide (NO) production and is attributed to improving cardiovascular health; Xia et al., 2013]. Given the proposed impact of SIRT1 activation, resveratrol could promote cell death of cancers by interfering with the expression of androgen and estrogen mediated genes as well as activating pro-apoptotic genes (such as BIM; Chen et al., 2010) through FOXO-mediated DNA binding.

In cancerous cell lines, the cytoprotective genes NQ01 (Yang et al., 2003; Jones et al., 2005), and PRDX1, as well as MGST1 and GSTA2 were induced by resveratrol treatment (Jones et al., 2005). These genes are transcribed by NRF2, a member of the NRF transcription factor family. SIRT1 deacetylates NRF family members, therefore, it could be that the induction of these genes in response to resveratrol is the result of SIRT1 activation of NRF2. Furthermore, JUNB, HSP40, SERP1, and $S T C H$ were up-regulated in response to resveratrol, indicating cellular stress, with resveratrol inducing cell cycle arrest and apoptosis at higher doses (Jones et al., 2005). Low levels of resveratrol may prime cells to deal with DNA-damage causing agents; however, at higher levels become a stress itself.

Resveratrol may also mirror the function of CR and promote health and longevity at the genetic level by interfering with pro-inflammatory signaling pathways. In healthy cells and tissues, resveratrol is able to block TNF-induced activation of the nuclear transcription factor NF- $\kappa$, which regulates genes involved in inflammation, cytoprotection and carcinogenesis (Busch et al., 2012). This is likely through the activation of SIRT1 mediated deacetylation of the p65/RelA subunit of NF-кB. In human tenocytes, resveratrol suppressed IL-1b induced activation of NF-KB and PI3K, inhibiting genes involved in inflammation and apoptosis (Busch et al., 2012). Resveratrol further inhibited IL-1b induced NF- $\mathrm{BB}$ and PI3K activation through inhibition of IKK, IКBa phosphorylation and inhibition of nuclear translocation of $\mathrm{NF}-\kappa \mathrm{B}$, implicating $\mathrm{PI} 3 \mathrm{~K}$ signaling as involved in the downstream impact of resveratrol (Busch et al., 2012; Ren et al., 2013). Resveratrol, as with other mimetics of CR, has been documented to have varied effects between healthy and cancer cell lines. In myeloid cells (U-937), Jurkat and epithelial cells (Hela and H4) resveratrol suppressed TNFinduced phosphorylation and nuclear translocation of p65/RelA. Also suppressed by resveratrol are AP-1,TNF-induced activation of mitogen-activation protein kinase kinase (MAPKK), TNFinduced cytotoxicity and caspase activation (Manna et al., 2000). Resveratrol activated p53 and influenced gene expression in LnCaP cells, impacting 34 transcripts being either up- or downregulated. Many of the transcripts were involved with apoptosis [including programmed cell death factor 2 (PDCD-2), p300, Apaf-1, CPP32, PIG 7, PIG8, BAK protein, and p57(Kip2)] (Narayanan et al., 2003), with resveratrol further impacting gene expression (Le Corre et al., 2006), decreasing proliferation (Delmas et al., 2000), and inducing apoptosis (Niles et al., 2003) in a number of human cancers. This change in gene expression was coincident with decreased activation of NF- $\kappa$ B (Narayanan et al., 2003). Genes involved in DNA damage, cell cycle and oxidative stress were were also noted to be down regulated (Narayanan et al., 2003). These observations demonstrate that resveratrol is able to mimic CR by SIRT-mediated deacetylation of pro-inflammatory complexes such as NF- $\mathrm{B}$ in normal cells while possibly having the opposite pro-apoptotic effect in cancer lines. 


\section{CATECHINS}

In Japan, subpopulations are long-lived; this may be due to the ingestion of large quantities of green tea enriched for in polyphenolic compounds. One of the most well studied of these polyphenolic compounds is (-)-epigallocatechin-3-gallate (EGCG). Like other polyphenols, it has free radical scavenging capabilities and inhibits NF- $\mathrm{kB}$ mediated inflammatory responses in a variety of systems (Akhtar and Haqqi, 2011; Han et al., 2012; Jiang et al., 2012), undoubtedly a major factor in this observed longevity. However, EGCG has other ascribed impacts that may contribute to increased longevity. EGCG reduces levels of adipogenesis-related transcriptional factors, such as $\mathrm{C} / \mathrm{EBP} \beta$ and PPAR, of differentiating 3T3-L1 preadipocytes (Kao et al., 2006). EGCG treatment of breast cancer cells can reactivate estrogen receptor (ER)- $\alpha$ through a reversal of epigenetic silencing, leading to apoptosis (Li et al., 2010b). In addition EGCG also directly and indirectly inhibits DNA methyl transferases (DNMTs) causing the loss of methylation from the $p 16^{\text {ink }}$ promoter, retinoic acid receptor $\beta$ (RAR $\beta$ ), and the DNA mismatch repair gene human mutL homolog 1 (hMLH1). EGCG also promotes the repression of the gene encoding for a subunit of the human telomerase enzyme, hTERT, resulting in cancer cell senescence (Berletch et al., 2008), similar to suppression induced by glucose restriction of lung fibroblasts (Suzuki et al., 2011). A comprehensive review of EGCG functions and modes is given by Singh and colleagues describing the impact of this compound on cell cycle inhibition, apoptosis and growth factor signaling (Singh B. N. et al., 2011; Singh H. et al., 2011).

Unlike rapamycin or resveratrol, polyphenols in general may not promote longevity per se, but have anti-cancer properties. For example, genistein also stimulated the loss of $h T E R T$ expression by increasing $\mathrm{H} 3 \mathrm{~K} 9 \mathrm{me} 3$ and decreasing $\mathrm{H} 3 \mathrm{~K} 4 \mathrm{me} 2$ within the promoter region, preventing E2F-1-mediated transcriptional activation (Li et al., 2009), leading to decreased cancer cell proliferation. In addition, many of the actions of EGCG are related to promoting apoptosis or senescence of cancer cells through changes in epigenetic status (Berletch et al., 2008; Singh H. et al., 2011). Although these compounds are exciting potential chemotherapeutic agents, they may not be directly acting as anti-aging compounds.

\section{METFORMIN}

Metformin, a compound derived from the French Lilac (G. officinalis) and chemically known as N,NDimethylimidodicarbonimidic diamide, is a guanidine-based hypoglycemic agent commonly used in treating patients with type II diabetes (T2D; Witters, 2001) by inhibiting hepatic gluconeogenesis and decreasing insulin levels (Hundal et al., 2000; Zhou et al., 2001). Despite being such a widely used compound, the specific mechanisms by which metformin act at the molecular/cellular level remain unconfirmed. Regardless, evidence does indicate that metformin functions, at least in part, via an AMPK-dependent pathway (Zhou et al., 2001). It is unlikely that metformin directly binds to either AMPK or its activator LKB1 as the drug does not affect phosphorylation of
AMPK by LKB1 in a cell-free assay (Hardie, 2006). Metformin likely influences AMPK levels by modulating ATP production by mitochondria. Evidence to support this hypothesis indicates that metformin induces mild and specific inhibition of the mitochondrial respiratory-chain complex I (El-Mir et al., 2000; Owen et al., 2000). Metformin has further been suggested to act through a number of AMPK-independent pathways such as via DNA-damage inducible transcript 4 (DDIT-4; Ben Sahra et al., 2011). Although the positive health benefits in regards to $\mathrm{T} 2 \mathrm{D}$ and potentially health and lifespan are well documented, how this is facilitated through numerous pathways and secondary effects is unclear. This metformin-mediated disruption of mitochondrial function may parallel CR through increased AMP:ATP ratios leading to AMPK activation (Canto and Auwerx, 2011) and mTOR inhibition.

Recent evidence has highlighted metformin as both a potential anti-cancer agent and as a promising target in promoting increased health and lifespan. Numerous studies report increased apoptosis and decreased proliferation of various cancer cell lines (e.g., lung; Ashinuma et al., 2012, retinoblastoma; Brodowska et al., 2014, and oesophageal squamous cell carcinoma; Feng et al., 2014) in response to metformin, and T2D patients treated with metformin have a lower incidence of cancer compared to control groups (Evans et al., 2005). This is promising given the extensive links between cancer and aging; however, healthy model organisms treated with metformin have shown varied responses, with lifespan extension occurring in C. elegans (Onken and Driscoll, 2010; Cabreiro et al., 2013) and M. musculus (Martin-Montalvo et al., 2013), whilst D. melanogaster (Slack et al., 2012) and R. norvegicus (Smith et al., 2010) demonstrated no change.

What impact does metformin have on genome function to promote health? Under conditions of excess nutrients AMPK and SIRT1 are down regulated. Metformin results in the activation of both these proteins (Nelson et al., 2012; Arunachalam et al., 2014) similar to CR (Cohen et al., 2004; Canto and Auwerx, 2011). The metformin-mediated activation of AMPK and SIRT1 deacetylation of $\mathrm{p} 53$ decreases its function in the human hepatic carcinoma cell line, HepG2 (Nelson et al., 2012). In addition, metformin appears to reduce levels of oxidative stress, impeding p53 activation. It also decreased a trigger for p53 accumulation, cytosolic oxidative stress and increased deacetylation of p53 at a SIRT1 targeted site (Nelson et al., 2012). Furthermore, mouse microvascular endothelial cells (MMEC) that had been exposed to high glucose were treated with metformin. This treatment up-regulated SIRT1 expression which is normally repressed by high glucose, modulating downstream targets of SIRT1 (FoxO1 and p53/p21) and protecting endothelial cells from entering premature senescence (Arunachalam et al., 2014). In blood mononuclear cells (MNC) of patients with carotid artery atherosclerosis, metformin ameliorates the pro-inflammatory response decreasing $I L-6, T N F-\alpha$ mRNA levels and attenuated NF- $\kappa B$ DNA binding activity (Xu et al., 2015). Metformin did not alter p65/RelA protein levels but resulted in decreased acetylation, likely through SIRT1-mediated deacetylation (Xu et al., 2015). Additionally, Saa1 and Saa2 genes, associated with the inflammatory response, are down-regulated in the muscle 
and liver of metformin-treated mice. A decrease in inflammatory markers (attenuated expression of the $N F-\kappa B$ gene, resulted in decreased NF- $\mathrm{KB}$ and JNK) was also observed (MartinMontalvo et al., 2013). This is coincident with a significant upregulation of cytokine-inducible SH2-containing protein (CISH), a negative regulator of cytokine signaling (Martin-Montalvo et al., 2013). Metformin has also been associated with the induction of stress-response and antioxidant-linked proteins, including SOD2, TrxR1, NQ01 and NQ02 in mice livers (Martin-Montalvo et al., 2013). Furthermore, metformin treatment decreased production of IL-1 $\beta$, increased induction of anti-inflammatory IL-10 and inhibited ROS in macrophages (Algire et al., 2012; Kelly et al., 2015). Contradictory to CR, metformin resulted in increased levels of ROS which up-regulated the expression of the UCP2 transcripts in epididymal white adipose tissue of mice or in 3T3-L1 adipocytes (Anedda et al., 2008). Taken together, these data indicate that metformin may inhibit multiple proinflammatory pathways, through activation of SIRT1 and the repression of NF- $\mathrm{KB}$ in addition to the up-regulation of $\mathrm{CISH}$, as part of the mechanism influencing health and longevity. As with rapamycin and CR, however, different systems and cell types may result in differing responses.

The expression of the Selenoprotein P (SeP) encoding SEPP1 gene leads to increased potential in developing T2D (Takayama et al., 2014). Promoter analysis and subsequent reporter assays of this gene demonstrates binding sites for FOXO3a to facilitate the expression of this gene. Metformin treatment disrupted FOXO mediated expression of this gene through direct phosphorylation by activated AMPK (Takayama et al., 2014). Daf-16 knockouts in C. elegans leads to increased lifespan by disruption of the insulin-like pathway (Greer and Brunet, 2005). CR results in FOXO3a hyperphosphorylation by AMPK and its exclusion from the nucleus. Metformin-mediated activation of AMPK also leads to hyperphosphorylation of FOXO3a, nuclear exclusion and up-regulation of mitochondrial gene expression (Greer and Brunet, 2005). However, knockout of daf-16/FOXO still resulted in an increase in median lifespan, demonstrating that this transcription factor is dispensable for metformin mediated lifespan extension (Onken and Driscoll, 2010). Therefore, metformin may be acting through a CR conferred pathway. In eat-2 knock-outs (which impair the ability of worms to feed) treated with metformin, no health or lifespan benefits were observed and detrimental effects similar to those of extreme CR were documented. Regardless, the extension of lifespan requires functional AMPK (Onken and Driscoll, 2010) indicating that this is a critical molecule in metformin mediated lifespan extension.

Knockout and mutational analysis of the C. elegans homolog of AMPK, aak-2, demonstrates that this protein is essential for metformin-associated lifespan extension (Onken and Driscoll, 2010). Furthermore, the protein threonine kinase, LKB1, directly phosphorylates and activates AMPK in response to metformin. In C. elegans, PAR-4 (the LKB1 homolog) mutants treated with metformin conferred no health or lifespan benefits (Onken and Driscoll, 2010) demonstrating the importance of this kinase in mediating AMPK function. In the absence of this LKB1 activity, metformin treatment resulted in decreased lifespan. LKB1 inactivation has been suggested to be regulated by SIRT1, influencing its cytosolic localization, association with the LKB1 activator STE20-related adaptor (STRAD), kinase activity and its ability to activate AMPK (Lan et al., 2008). This links the interplay between AMPK, LKB1, and SIRT1 as key mediators of longevity across model organisms.

To ascertain what impact metformin treatment is having genome-wide, transcript profiles from LoVo colon cancer cells were assessed by microarray analysis (He et al., 2015). At $8 \mathrm{~h}$, $10 \mathrm{mM}$ metformin resulted in 134 differentially expressed genes, whilst at $24 \mathrm{~h} 3061$ genes altered expression. Concentration of metformin also demonstrated alternative impacts on health and lifespan with $0.1 \%(\mathrm{w} / \mathrm{w})$ metformin in the diets of C57BL/6 increasing lifespan whilst $1 \%(\mathrm{w} / \mathrm{w})$ metformin decreased lifespan (Martin-Montalvo et al., 2013). In B6C3F1 mice, lifespan extension was also observed; however, the levels were less significant (Martin-Montalvo et al., 2013). Microarray analyses of the muscle and liver cells of metformin-fed mice revealed a transcriptome profile shifting toward that, but not identical to, caloric restriction by 30 weeks. Although $\mathrm{CISH}$ was consistently one of the most up-regulated genes in both tissues (MartinMontalvo et al., 2013), other genes were up-regulated in one but not the other (e.g., SOCS2 up-regulated in liver, DDIT4 in muscle). Therefore, the effects of metformin are not only strain/tissue-, dose- and time-dependent, but may also not directly mimic CR.

Gene ontology (GO) term enrichment of LoVo cells treated with metformin revealed up-regulated genes enriched for processes such as RNA processing and regulation of cellular protein metabolic process whilst down-regulated genes demonstrated enrichment for various cell cycle processes at $8 \mathrm{~h}$. At $24 \mathrm{~h}$, up-regulated genes were enriched for in pathways of cell activity (e.g., protein modification, induction of apoptosis and response to reactive oxygen species; He et al., 2015). Microarray analysis of mouse liver tissues following $0.1 \%(\mathrm{w} / \mathrm{w})$ metformin treatment revealed down-regulation of genes associated with autophagy, and apoptosis in mice (Martin-Montalvo et al., 2013). Although this is an opposite impact to that observed in LoVo cells, it is logical and in agreement with the proposal that metformin induced apoptosis in cancer cell lines, whilst in healthy tissues, promotes cell survival, likely via SIRT1/FOXO axis.

\section{SPERMIDINE}

In general, polyamines are polycationic molecules that interact with negatively charged polymers such as DNA, RNA and proteins and can be found in a large number of eukaryotic and prokaryotic organisms (reviewed in Minois, 2014). Polyamines decrease with aging in several mouse tissues (Nishimura et al., 2006) and in the aging human basal ganglia (Vivo et al., 2001). Although polyamines, including spermidine, are naturally produced within cells, ingestion of polyamines from the diet can impact gene expression and chromatin organization associated with increased healthspan and longevity (Minois et al., 2011). The specific mechanisms by which these 
molecules facilitate changes in gene expression are indirect or have not been elucidated. Like CR, and other nutraceuticals that impact lifespan, spermidine reduces the expression of pro-inflammatory genes. This suppression of pro-inflammatory genes is hypothesized to be the result of sequestered NF- $\mathrm{KB}$ subunit p65 in the cytoplasm, preventing the activation of target genes (Choi and Park, 2012). In 3T3-L1 cells, spermidine has been shown to directly interact with the acidic nuclear phosphoprotein 32 (ANP32; Hyvonen et al., 2013). Upon spermidine interaction, ANP32 releases the RNA binding protein $\mathrm{HuR}$ which then binds and facilitates the translation of C/EBP-b. This increase in C/EBP-b speculated to further drive the expression of genes encoding the transcription factors PPAR- $\gamma$ and SREBP-1c leading to adipocyte differentiation (Hyvonen et al., 2013). Furthermore, transcriptome profiling of cells depleted of polyamines demonstrated increased expression of cell cycle control proteins p21, Mdm2, and Gadd45 as well as reduced expression of cyclin D1 (Landau et al., 2012). However, it is unclear if these changes were secondary effect of polyamine depletion activating the unfolded protein stress response. These stress responses and resumption of cell growth were quickly reversed upon the addition of spermidine.

Spermidine also appears to impact global acetylation levels of histones. In yeast, all histone $\mathrm{H} 3$ lysine residues studied showed decreased levels of acetylation following spermidine treatment in addition to decreased levels of ROS. This hypoacetylation is believed to be due to spermidine mediated inhibition of histone acetyl transferases (HATs) leading to increased expression of the autophagy-related ATG genes (Eisenberg et al., 2009). Furthermore, keratinocytes from mice over-expressing enzyme promoting spermidine production demonstrated an overall reduction in acetylation levels indicating a further impact on gene expression. Although this decrease in acetylation levels as well as the inhibition of NF- $\kappa \mathrm{B}$ is reminiscent of SIRT1 activation, recent research has proposed that spermidine and other SIRT1 activators (such as resveratrol) function via differing pathways, but both impacting global protein acetylation (Morselli et al., 2011). Spermidine also has a complex nature with regards to cancer cells. In some cancers polyamines synthesis is upregulated resulting in an indirect increase p300-associated HAT activity, altering chromatin structure favoring neoplastic process (Hobbs et al., 2002).

\section{ASPIRIN}

Aspirin, also known as acetylsalicylic acid (ASA), is a member of the non-steroidal anti-inflammatory (NSAID) drug family and is well known for its inhibitory effect on COX-2 gene expression. COX-2 encodes the cyclooxygenase 2 enzyme which functions to convert arachidonic acid to prostaglandins which further function in pain and inflammatory responses. Nuclear translocation of activated NF- $\mathrm{KB}$ promotes the transcription of target genes such as Cox-2, iNOS, VCAM-1, and ICAM-1. Low doses of ASA fed to old rats appeared to ameliorate the NFmediated pro-inflammatory response in kidneys by preventing
I $\mathrm{B}$ degradation, leading to cytoplasmic retention of NF- $\kappa \mathrm{B}$ (Jung et al., 2006). In addition, ASA also appeared to inhibit the nuclear translocation of the complex containing thioredoxin (Trx) and redox factor-1 (Ref-1) which enable DNA binding of NF- $\kappa$ B. Investigation into other compounds closely related to ASA from the NSAID family have focused on the impact of these drugs on NF- $\mathrm{KB}$ function. Furthermore, treatment of breast cancer cells with the physiological achievable concentration of $100 \mu$ M ASA increased levels of p53 acetylation and increased the expression of $\mathrm{p}_{21}{ }^{\mathrm{CIP}}$ (cell cycle arrest) and Bax (pro-apoptotic). ASA may further increase health and lifespan by inducing the expression of pro-apoptotic genes in cancer cells. For example, ASA has been documented to up regulate calpain expression in cervical carcinomas. Calpains are a class of non-lysosomal cysteine proteases involved with a number of cellular processes including glucose homeostasis. Furthermore, calpains exhibit cross talk with the pro-apoptotic protease caspase-3 (Lee et al., 2008). However, the response of cells/tissues to ASA may not be straight forward. Microarray analysis of HT29 colon cancer cells demonstrates significantly different transcriptome profiles when treated with $50 \mu \mathrm{M}, 500 \mu \mathrm{M}$, or $5 \mathrm{mM}$ of ASA (Hardwick et al., 2004). These observations indicate that ASA is potentially useful as a chemo-preventative agent for cancers and, therefore, involved in promoting health, but the dose of the compound may alter gene expression profiles leading to alternative, possibly undesired outcomes. In addition, risk-benefit research into the use of ASA indicates that patients with disease that make them prone to cancers, such as familial adenomatous polyposis or Lynch syndrome, are not protected (Alfonso et al., 2009). Other cancer types, such as adenomas, do show statistically significant alterations in response to ASA. These observations, indicate that ASA does promote changes in genome function leading to increased health and possibly the prevention of specific cancers; however, this role in specifically increasing longevity per se is unclear.

\section{CONCLUSIONS}

It is clear that CR results in decreased energy and changes in cellular AMP:ATP and NAD:NADH ratios. Compounds that mimic CR do so by impacting cellular function resulting energy readouts or interfering with signaling down-stream cellular energy levels. The main proteins that appear central to mediating this response are AMPK and SIRT1 which regulate cycles of deacetylation and phosphorylation of a large number of cytosolic and nuclear proteins to control gene expression and cellular functions. Many of the CR mimetics of naturally occurring compounds identified either modulate SIRT1/AMPK function or, for example with rapamycin, target downstream signaling hubs to mediate potential health and lifespan effects. Of these targets NF-кB and the FOXO family of transcription factors, are pivotal in promoting decreased cell proliferation and increased maintenance in normal cells, while facilitating apoptosis and cell death in cancer cells. Furthermore, although all compounds appear to confer life and healthspan extending impacts across numerous cell types and model 
organisms via this SIRT1/AMPK interaction, the downstream impact on genome function (gene expression) is varied, across cell-type, organism-type, and compound-type in addition to variations in experimental details (such as exposure times, drug concentrations). This suggests that although mechanisms mediating health and lifespan in response to CR and these compounds are similar, the effects on gene expression mean that these compounds may not be direct mimetics of $\mathrm{CR}$ or of one another.

\section{REFERENCES}

Aguilar-Arnal, L., Katada, S., Orozco-Solis, R., and Sassone-Corsi, P. (2015). $\mathrm{NAD}(+)$-SIRT1 control of H3K4 trimethylation through circadian deacetylation of MLL1. Nat. Struct. Mol. Biol. 22, 312-318. doi: 10.1038/nsmb.2990

Akhtar, N., and Haqqi, T. M. (2011). Epigallocatechin-3-gallate suppresses the global interleukin-1beta-induced inflammatory response in human chondrocytes. Arthritis Res. Ther. 13:R93. doi: 10.1186/ar3368

Alfonso, L. F., Srivenugopal, K. S., Arumugam, T. V., Abbruscato, T. J., Weidanz, J. A., and Bhat, G. J. (2009). Aspirin inhibits camptothecin-induced p21CIP1 levels and potentiates apoptosis in human breast cancer cells. Int. J. Oncol. 34, 597-608. doi: 10.3892/ijo_00000185

Algire, C., Moiseeva, O., Deschenes-Simard, X., Amrein, L., Petruccelli, L., Birman, E., et al. (2012). Metformin reduces endogenous reactive oxygen species and associated DNA damage. Cancer Prev. Res. 5, 536-543. doi: 10.1158/19406207.CAPR-11-0536

Anderson, R. M., Bitterman, K. J., Wood, J. G., Medvedik, O., and Sinclair, D. A. (2003). Nicotinamide and PNC1 govern lifespan extension by calorie restriction in Saccharomyces cerevisiae. Nature 423, 181-185. doi: 10.1038/ nature 01578

Anedda, A., Rial, E., and Gonzalez-Barroso, M. M. (2008). Metformin induces oxidative stress in white adipocytes and raises uncoupling protein 2 levels. J. Endocrinol. 199, 33-40. doi: 10.1677/JOE-08-0278

Arunachalam, G., Samuel, S. M., Marei, I., Ding, H., and Triggle, C. R. (2014). Metformin modulates hyperglycaemia-induced endothelial senescence and apoptosis through SIRT1. Br. J. Pharmacol. 171, 523-535. doi: 10.1111/bph.12496

Ashinuma, H., Takiguchi, Y., Kitazono, S., Kitazono-Saitoh, M., Kitamura, A., Chiba, T., et al. (2012). Antiproliferative action of metformin in human lung cancer cell lines. Oncol. Rep. 28, 8-14. doi: 10.3892/or.2012.1763

Baker, D. J., Wijshake, T., Tchkonia, T., LeBrasseur, N. K., Childs, B. G., van de Sluis, B., et al. (2011). Clearance of p16Ink4a-positive senescent cells delays ageing-associated disorders. Nature 479, 232-236. doi: 10.1038/ nature 10600

Bass, T. M., Weinkove, D., Houthoofd, K., Gems, D., and Partridge, L. (2007). Effects of resveratrol on lifespan in Drosophila melanogaster and Caenorhabditis elegans. Mech. Ageing Dev. 128, 546-552. doi: 10.1016/j.mad.2007.07.007

B'Chir, W., Maurin, A. C., Carraro, V., Averous, J., Jousse, C., Muranishi, Y., et al. (2013). The eIF2alpha/ATF4 pathway is essential for stress-induced autophagy gene expression. Nucleic Acids Res. 41, 7683-7699. doi: 10.1093/nar/gkt563

Bektas, A., Zhang, Y., Lehmann, E., Wood, J. W. III, Becker, K. G., Madara, K., et al. (2014). Age-associated changes in basal NF- $\kappa B$ function in human CD4+ T ymphocytes via dysregulation of PI3 kinase. Aging 6, 957-969. doi: 10.18632/aging. 100705

Ben Sahra, I., Regazzetti, C., Robert, G., Laurent, K., Le Marchand-Brustel, Y., Auberger, P., et al. (2011). Metformin, independent of AMPK, induces mTOR inhibition and cell-cycle arrest through REDD1. Cancer Res. 71, 4366-4372. doi: 10.1158/0008-5472.CAN-10-1769

Berletch, J. B., Liu, C., Love, W. K., Andrews, L. G., Katiyar, S. K., and Tollefsbol, T. O. (2008). Epigenetic and genetic mechanisms contribute to telomerase inhibition by EGCG. J. Cell. Biochem. 2, 509-519. doi: 10.1002/jcb.21417

\section{AUTHOR CONTRIBUTIONS}

ZG, JP, and CE constructed and wrote the manuscript. All authors contributed to the editing and final submission of the document.

\section{FUNDING}

This work was supported by the NSERC (grant number RGPIN2015-04930) Discovery Grant program.

Bernardi, R., Guernah, I., Jin, D., Grisendi, S., Alimonti, A., Teruya-Feldstein, J., et al. (2006). PML inhibits HIF-1alpha translation and neoangiogenesis through repression of mTOR. Nature 442, 779-785. doi: 10.1038/nature05029

Bjedov, I., Toivonen, J. M., Kerr, F., Slack, C., Jacobson, J., Foley, A., et al. (2010). Mechanisms of life span extension by rapamycin in the fruit fly Drosophila melanogaster. Cell Metab. 11, 35-46. doi: 10.1016/j.cmet.2009.11.010

Blagosklonny, M. V. (2010). Calorie restriction: decelerating mTOR-driven aging from cells to organisms (including humans). Cell Cycle 9, 683-688. doi: 10.4161/cc.9.4.10766

Bordone, L., Cohen, D., Robinson, A., Motta, M. C., van Veen, E., Czopik, A., et al. (2007). SIRT1 transgenic mice show phenotypes resembling calorie restriction. Aging Cell 6, 759-767. doi: 10.1111/j.1474-9726.2007.00335.x

Brodowska, K., Theodoropoulou, S., Meyer Zu Hörste, M., Paschalis, E. I., Takeuchi, K., Scott, G., et al. (2014). Effects of metformin on retinoblastoma growth in vitro and in vivo. Int. J. Oncol. 45, 2311-2324. doi: $10.3892 /$ ijo. 2014.2650

Brown-Borg, H. M., and Bartke, A. (2012). GH and IGF1: roles in energy metabolism of long-living GH mutant mice. J. Gerontol. A Biol. Sci. Med. Sci. 67, 652-660. doi: 10.1093/gerona/gls086

Brown, J. D., and Plutzky, J. (2007). Peroxisome proliferator-activated receptors as transcriptional nodal points and therapeutic targets. Circulation 115, 518-533. doi: 10.1161/CIRCULATIONAHA.104.475673

Brunet, A., Sweeney, L. B., Sturgill, J. F., Chua, K. F., Greer, P. L., Lin, Y., et al. (2004). Stress-dependent regulation of FOXO transcription factors by the SIRT1 deacetylase. Science 303, 2011-2015. doi: 10.1126/science.1094637

Bunpo, P., Cundiff, J. K., Reinert, R. B., Wek, R. C., Aldrich, C. J., and Anthony, T. G. (2010). The eIF2 kinase GCN2 is essential for the murine immune system to adapt to amino acid deprivation by asparaginase. J. Nutr. 140, 2020-2027. doi: 10.3945/jn.110.129197

Busch, F., Mobasheri, A., Shayan, P., Lueders, C., Stahlmann, R., and Shakibaei, M. (2012). Resveratrol modulates IL-1 $\beta$-induced PI3K and NF-кB signalling pathways in human tenocytes. J. Biol. Chem. 287, 38050-38063. doi: 10.1074/jbc.M112.377028

Cabelof, D. C., Yanamadala, S., Raffoul, J. J., Guo, Z., Soofi, A., and Heydari, A. R. (2003). Caloric restriction promotes genomic stability by induction of base excision repair and reversal of its age-related decline. DNA Repair (Amst). 2, 295-307. doi: 10.1016/S1568-7864(02)00219-7

Cabreiro, F., Au, C., Leung, K. Y., Vergara-Irigaray, N., Cocheme, H. M., Noori, T., et al. (2013). Metformin retards aging in C. elegans by altering microbial folate and methionine metabolism. Cell 153, 228-239. doi: 10.1016/j.cell.2013.02.035

Calabrese, V., Cornelius, C., Cuzzocrea, S., Iavicoli, I., Rizzarelli, E., and Calabrese, E. J. (2011). Hormesis, cellular stress response and vitagenes as critical determinants in aging and longevity. Mol. Aspects Med. 32, 279-304. doi: 10.1016/j.mam.2011.10.007

Canto, C., and Auwerx, J. (2011). Calorie restriction: is AMPK a key sensor and effector? Physiology 26, 214-224. doi: 10.1152/physiol.00010.2011

Cao, K., Graziotto, J. J., Blair, C. D., Mazzulli, J. R., Erdos, M. R., Krainc, D., et al. (2011). Rapamycin reverses cellular phenotypes and enhances mutant protein clearance in Hutchinson-Gilford progeria syndrome cells. Sci. Transl. Med. 3:89ra58. doi: 10.1126/scitranslmed.3002346

Chantranupong, L., Wolfson, R. L., and Sabatini, D. M. (2015). Nutrient-sensing mechanisms across evolution. Cell 161, 67-83. doi: 10.1016/j.cell.2015.02.041 
Chen, D., Thomas, E. L., and Kapahi, P. (2009). HIF-1 modulates dietary restriction-mediated lifespan extension via IRE-1 in Caenorhabditis elegans. PLoS Genet. 5:e1000486. doi: 10.1371/journal.pgen.1000486

Chen, Q., Ganapathy, S., Singh, K. P., Shankar, S., and Srivastava, R. K. (2010). Resveratrol induces growth arrest and apoptosis through activation of FOXO transcription factors in prostate cancer cells. PLoS ONE 5:e15288. doi: 10.1371/journal.pone.0015288

Chin, Y., Hsieh, M., Yang, S., Tsai, P., Wang, S., Wang, C., et al. (2014). Antiproliferative and gene expression actions of resveratrol in breast cancer cells in vitro. Oncotarget 5, 12891-12907. doi: 10.18632/oncotarget.2632

Choi, K. M., Kwon, Y. Y., and Lee, C. K. (2013). Characterization of global gene expression during assurance of lifespan extension by caloric restriction in budding yeast. Exp. Gerontol. 48, 1455-1468. doi: 10.1016/j.exger.2013.10.001

Choi, Y. H., and Park, H. Y. (2012). Anti-inflammatory effects of spermidine in lipopolysaccharide-stimulated BV2 microglial cells. J. Biomed. Sci. 19:31. doi: 10.1186/1423-0127-19-31

Cohen, H. Y., Miller, C., Bitterman, K. J., Wall, N. R., Hekking, B., Kessler, B., et al. (2004). Calorie restriction promotes mammalian cell survival by inducing the SIRT1 deacetylase. Science 305, 390-392. doi: 10.1126/science.1099196

Coppe, J. P., Desprez, P. Y., Krtolica, A., and Campisi, J. (2010). The senescenceassociated secretory phenotype: the dark side of tumor suppression. Annu. Rev. Pathol. 5, 99-118. doi: 10.1146/annurev-pathol-121808-102144

Daitoku, H., Hatta, M., Matsuzaki, H., Aratani, S., Ohshima, T., Miyagishi, M., et al. (2004). Silent information regulator 2 potentiates Foxol-mediated transcription through its deacetylase activity. Proc. Natl. Acad. Sci. U.S.A. 101, 10042-10047. doi: 10.1073/pnas.0400593101

Das, A., Durrant, D., Koka, S., Salloum, F. N., Xi, L., and Kukreja, R. C. (2014). Mammalian target of rapamycin (mTOR) inhibition with rapamycin improves cardiac function in type 2 diabetic mice: potential role of attenuated oxidative stress and altered contractile protein expression. J. Biol. Chem. 289, 4145-4160. doi: 10.1074/jbc.M113.521062

Delmas, D., Jannin, B., Cherkaoui Malki, M., and Latruffe, N. (2000). Inhibitory effect of resveratrol on the proliferation of human and rat hepatic derived cell lines. Oncol. Rep. 7, 847-899. doi: 10.3892/or.7.4.847

Demidenko, Z. N., Zubova, S. G., Bukreeva, E. I., Pospelov, V. A., Pospelova, T. V., and Blagosklonny, M. V. (2009). Rapamycin decelerates cellular senescence. Cell Cycle 8, 1888-1895. doi: 10.4161/cc.8.12.8606

Dumont, F. J., and Su, Q. (1996). Mechanism of action of the immunosuppressant rapamycin. Life Sci. 58, 373-395. doi: 10.1016/0024-3205(95)02233-3

Eisenberg, T., Knauer, H., Schauer, A., Buttner, S., Ruckenstuhl, C., CarmonaGutierrez, D., et al. (2009). Induction of autophagy by spermidine promotes longevity. Nat. Cell Biol. 11, 1305-1314. doi: 10.1038/ncb1975

El-Mir, M. Y., Nogueira, V., Fontaine, E., Averet, N., Rigoulet, M., and Leverve, X. (2000). Dimethylbiguanide inhibits cell respiration via an indirect effect targeted on the respiratory chain complex, I. J. Biol. Chem. 275, 223-228. doi: 10.1074/jbc.275.1.223

Endale, M., Park, S. C., Kim, S., Kim, S. H., Yang, Y., Cho, J. Y., et al. (2013). Quercetin disrupts tyrosine-phosphorylated phosphatidylinositol 3-kinase and myeloid differentiation factor-88 association, and inhibits MAPK/AP-1 and IKK/NF-kappaB-induced inflammatory mediators production in RAW 264.7 cells. Immunobiology 218, 1452-1467. doi: 10.1016/j.imbio.2013.04.019

Evans, J. M. M., Donnelly, L. A., Emslie-Smith, A. M., Alessi, D. R., and Morris, A. D. (2005). Metformin and reduced risk of cancer in diabetic patients. BMJ 330, 1304-1305. doi: 10.1136/bmj.38415.708634.F7

Fabrizio, P., Gattazzo, C., Battistella, L., Wei, M., Cheng, C., McGrew, K., et al. (2005). Sir2 blocks extreme life-span extension. Cell 123, 655-667. doi: 10.1016/j.cell.2005.08.042

Fang, L., Wang, H., Zhou, L., and Yu, D. (2011). FOXO3a reactivation mediates the synergistic cytotoxic effects of rapamycin and cisplatin in oral squamous cell carcinoma cells. Toxicol. Appl. Pharmacol. 251, 8-15. doi: 10.1016/j.taap.2010.11.007

Feng, Y., Ke, C., Tang, Q., Dong, H., Zheng, X., Lin, W., et al. (2014). Metformin promotes autophagy and apoptosis in esophageal squamous cell carcinoma by downregulating Stat3 signaling. Cell Death Dis. 5:e1088. doi: 10.1038/cddis.2014.59

Fok, W. C., Livi, C., Bokov, A., Yu, Z., Chen, Y., Richardson, A., et al. (2014). Shortterm rapamycin treatment in mice has few effects on the transcriptome of white adipose tissue compared to dietary restriction. Mech. Ageing Dev. 140, 23-29. doi: 10.1016/j.mad.2014.07.004

Fontana, L., and Klein, S. (2007). Aging, adiposity, and calorie restriction. JAMA 297, 986-994. doi: 10.1001/jama.297.9.986

Fontana, L., Villareal, D. T., Das, S. K., Smith, S. R., Meydani, S. N., Pittas, A. G., et al. (2015). Effects of 2-year calorie restriction on circulating levels of IGF-1, IGF-binding proteins and cortisol in nonobese men and women: a randomized clinical trial. Aging Cell 15, 22-27. doi: 10.1111/acel.12400

Fontana, L., Weiss, E. P., Villareal, D. T., Klein, S., and Holloszy, J. O. (2008). Long-term effects of calorie or protein restriction on serum IGF-1 and IGFBP-3 concentration in humans. Aging Cell 7, 681-687. doi: 10.1111/j.14749726.2008.00417.x

Fu, M., Liu, M., Sauve, A. A., Jiao, X., Zhang, X., Wu, X., et al. (2006). Hormonal control of androgen receptor function through SIRT1. Mol. Cell. Biol. 26, 8122-8135. doi: 10.1128/MCB.00289-06

Fu, Z. D., and Klaassen, C. D. (2014). Short-term calorie restriction feminizes the mRNA profiles of drug metabolizing enzymes and transporters in livers of mice. Toxicol. Appl. Pharmacol. 274, 137-146. doi: 10.1016/j.taap.2013.11.003

Furuyama, T., Nakazawa, T., Nakano, I., and Mori, N. (2000). Identification of the differential distribution patterns of mRNAs and consensus binding sequences for mouse DAF-16 homologues. Biochem. J. 349, 629-634. doi: 10.1042/bj3490629

Furuyama, T., Yamashita, H., Kitayama, K., Higami, Y., Shimokawa, I., and Mori, N. (2002). Effects of aging and caloric restriction on the gene expression of Foxo1, 3, and 4 (FKHR, FKHRL1, and AFX) in the rat skeletal muscles. Microsc. Res. Tech. 59, 331-334. doi: 10.1002/jemt.10213

Gallo, C. M., Smith, D. L., and Smith, J. S. (2004). Nicotinamide clearance by Pnc1 directly regulates Sir2-mediated silencing and longevity. Mol. Cell. Biol. 24, 1301-1312. doi: 10.1128/MCB.24.3.1301-1312.2004

Gardner, P. J., Joshi, L., Lee, R. W., Dick, A. D., Adamson, P., and Calder, V. L. (2013). SIRT1 activation protects against autoimmune T cell-driven retinal disease in mice via inhibition of IL-2/Stat5 signaling. J. Autoimmun. 42, 117-129. doi: 10.1016/j.jaut.2013.01.011

Gehm, B. D., McAndrews, J. M., Chen, P., and Jameson, L. (1997). Resveratrol, a polyphenolic compound found in grapes and wine, is an agonist for the estrogen receptor. Proc. Natl. Acad. Sci. U.S.A. 94, 14138-14143. doi: 10.1073/pnas.94.25.14138

Giannakou, M. E., and Partridge, L. (2004). The interaction between FOXO and SIRT1: tipping the balance towards survival. Trends Cell Biol. 14, 408-412. doi: 10.1016/j.tcb.2004.07.006

Gierman, H. J., Fortney, K., Roach, J. C., Coles, N. S., Li, H., Glusman, G., et al. (2014). Whole-genome sequencing of the world's oldest people. PLoS ONE 9:e112430. doi: 10.1371/journal.pone.0112430

Gillespie, Z. E., MacKay, K., Sander, M., Trost, B., Dawicki, W., Wickramarathna, A., et al. (2015). Rapamycin reduces fibroblast proliferation without causing quiescence and induces STAT5A/B-mediated cytokine production. Nucleus 6, 490-506. doi: 10.1080/19491034.2015.1128610

Gowans, G. J., and Hardie, D. G. (2014). AMPK: a cellular energy sensor primarily regulated by AMP. Biochem. Soc. Trans. 42, 71-75. doi: 10.1042/BST201 30244

Greer, E. L., and Brunet, A. (2005). FOXO transcription factors at the interface between longevity and tumor suppression. Oncogene 24, 7410-7425. doi: 10.1038/sj.onc.1209086

Greer, E. L., Maures, T. J., Ucar, D., Hauswirth, A. G., Mancini, E., Lim, J. P., et al. (2011). Transgenerational epigenetic inheritance of longevity in Caenorhabditis elegans. Nature 479, 365-371. doi: 10.1038/nature10572

Haas, B. S., Hart, R. W., Lu, M. H., and Lyn-Cook, B. D. (1993). Effects of caloric restrction in animals on cellular function, oncogene expression, and DNA metehylation in vitro. Mutat. Res. 295, 281-289. doi: 10.1016/09218734(93)90026-Y

Han, S. G., Han, S. S., Toborek, M., and Hennig, B. (2012). EGCG protects endothelial cells against PCB 126-induced inflammation through inhibition of AhR and induction of Nrf2-regulated genes. Toxicol. Appl. Pharmacol. 261, 181-188. doi: 10.1016/j.taap.2012.03.024

Hardie, D. G. (2006). Neither LKB1 nor AMPK are the direct targets of metformin. Gastroenterology 131:973; author reply 974-975. doi: 10.1053/j.gastro.2006.07.032 
Harding, H. P., Zhang, Y., Bertolotti, A., Zeng, H., and Ron, D. (2000). Perk is essential for translational regulation and cell survival during the unfolded protein response. Mol. Cell 5, 897-904. doi: 10.1016/S1097-2765(00)80330-5

Harding, H. P., Zhang, Y., Zeng, H., Novoa, I., Lu, P. D., Calfon, M., et al. (2003). An integrated stress response regulates amino acid metabolism and resistance to oxidative stress. Mol. Cell 11, 619-633. doi: 10.1016/S1097-2765(03)00105-9

Hardwick, J. C. H., van Santen, M., van den Brink, G. R., van Deventer, S. J. H., and Peppelenbosch, M. P. (2004). DNA Array analysis of the effects of aspirin on colon cancer cells: involvement of Rac1. Carcinogenesis 25, 1293-1298. doi: $10.1093 /$ carcin/bgh118

Harper, J. M., Leathers, C. W., and Austad, S. N. (2006). Does caloric restriction extend life in wild mice? Aging Cell 5, 441-449. doi: 10.1111/j.14749726.2006.00236.x

He, J., Wang, K., Zheng, N., Qiu, Y., Xie, G., Su, M., et al. (2015), Metformin suppressed the proliferation of LoVo cells and induced a timedependent metabolic and transcriptional alteration. Sci. Rep. 5:17423. doi: 10.1038/srep17423

Hobbs, C. A., Paul, B. A., and Gilmour, S. K. (2002). Deregulation of polyamine biosynthesis alters intrinsic histone acetyltransferase and deacetylase activities in murine skin and tumors. Cancer Res. 62, 67-74.

Hong, S. S., Lee, H., and Kim, K. (2004). HIF-1 $\alpha$ : a valid therapeutic target for tumor therapy. Cancer Res. Treat. 36, 343-353. doi: 10.4143/crt.2004.36.6.343

Howitz, K. T., Bitterman, K. J., Cohen, H. Y., Lamming, D. W., Lavu, S., Wood, J. G., et al. (2003). Small molecule activators of sirtuins extend Saccharomyces cerevisiae lifespan. Nature 425, 191-196. doi: 10.1038/nature01960

Hsieh, T. C., Burfeind, P., Laud, K., Backer, J. M., Traganos, F., Darzynkiewicz, Z., et al. (1999). Cell cycle effects and control of gene expression by resveratrol in human breast carcinoma cell lines with different metastatic potentials. Int. J. Oncol. 15, 245-297. doi: 10.3892/ijo.15.2.245

Hui, A. S., Bauer, A. L., Striet, J. B., Schnell, P. O., and Czyzyk-Krzeska, M. F. (2006). Calcium signaling stimulates translation of HIF-alpha during hypoxia. FASEB J. 20, 466-475. doi: 10.1096/fj.05-5086com

Hundal, R. S., Krssak, M., Dufour, S., Laurent, D., Lebon, V., Chandramouli, V., et al. (2000). Mechanism by which metformin reduces glucose production in type 2 diabetes. Diabetes 49, 2063-2069. doi: 10.2337/diabetes.49.12.2063

Hyvonen, M. T., Koponen, T., Weisell, J., Pietila, M., Khomutov, A. R., Vepsalainen, J., et al. (2013). Spermidine promotes adipogenesis of 3T3-L1 cells by preventing interaction of ANP32 with HuR and PP2A. Biochem. J. 453, 467-474. doi: 10.1042/BJ20130263

Issa, J.-P. J., Ahuja, N., Toyota, M., Bronner, M. P., and Brentnall, T. A. (2001). Accelerated age-related $\mathrm{CpG}$ island methylation in ulcerative colitis. Cancer Res. 61, 3573-3577.

Issa, J. P., Ottaviano, Y. L., Celano, P., Hamilton, S. R., Davidson, N. E., and Baylin, S. B. (1994). Methylation of the oesterogen receptor $\mathrm{CpG}$ island links ageing and neoplasia in human colon. Nat. Genet. 7, 536-540. doi: 10.1038/ng0894-536

Jiang, J., Mo, Z.-C., Yin, K., Zhao, G.-J., Lv, Y.-C., Ouyang, X.-P., et al. (2012). Epigallocatechin-3-gallate prevents TNF-alpha-induced NF-kappaB activation thereby upregulating ABCA1 via the Nrf2/Keap1 pathway in macrophage foam cells. Int. J. Mol. Med. 29, 946-956. doi: 10.3892/ijmm.2012.924

Jobin, C., Bradham, C. A., Russo, M. P., Juma, B., Narula, A. S., Brenner, D. A., et al. (1999). Circumin blocks cytokine-mediated NF-kB activation and proinflammatory gene expression by inhibiting inhibitory factor I-kB kinase activity. J. Immunol. 163, 3474-3483.

Johnson, A. A., Akman, K., Calimport, S. R., Wuttke, D., Stolzing, A., and de Magalhaes, J. P. (2012). The role of DNA methylation in aging, rejuvenation, and age-related disease. Rejuvenation Res. 15, 483-494. doi: 10.1089/rej.2012.1324

Jones, S. B., DePrimo, S. E., Whitfield, M. L., and Brooks, J. D. (2005). Resveratrolinduced gene expression profiles in human prostate cancer cells. Cancer Epidemiol. Biomarkers Prev. 14, 596-604. doi: 10.1158/1055-9965.EPI-04-0398

Jung, C. H., Ro, S. H., Cao, J., Otto, N. M., and Kim, D. H. (2010). mTOR regulation of autophagy. FEBS Lett. 584, 1287-1295. doi: 10.1016/j.febslet.2010.01.017

Jung, K. J., Kim, J. Y., Zou, Y., Kim, Y. J., Yu, B. P., and Chung, H. Y. (2006). Effect of short-term, low dose aspirin supplementation on the activation of proinflammatory NF-kappaB in aged rats. Mech. Ageing Dev. 127, 223-230. doi: 10.1016/j.mad.2005.09.029
Kabil, H., Partridge, L., and Harshman, L. G. (2007). Superoxide dismutase activities in long-lived Drosophila melanogaster females: chicol genotypes and dietary dilution. Biogerontology 8, 201-208. doi: 10.1007/s10522-006-9065-3

Kalani, R., Judge, S., Carter, C., Pahor, M., and Leeuwenburgh, C. (2006). Effects of caloric restriction and exercise on age-related, chronic inflammation assessed by c-reactive protein and interleukin-6. J. Gerentol. 61A, 211-217. doi: 10.1093/gerona/61.3.211

Kang, M. J., Kim, H. J., Kim, H. K., Lee, J. Y., Kim, D. H., Jung, K. J., et al. (2005). The effect of age and calorie restriction on HIF-1-responsive genes in aged liver. Biogerontology 6, 27-37. doi: 10.1007/s10522-004-7381-z

Kannan, K., and Fridell, Y. W. (2013). Functional implications of Drosophila insulin-like peptides in metabolism, aging, and dietary restriction. Front. Physiol. 4:288. doi: 10.3389/fphys.2013.00288

Kao, Y. H., Chang, H. H., Lee, M. J., and Chen, C. L. (2006). Tea, obesity, and diabetes. Mol. Nutr. Food Res. 50, 188-210. doi: 10.1002/mnfr.200500109

Kelly, B., Tannahill, G. M., Murphy, M. P., and O’Neil, L. A. J. (2015). Metformin inhibits the production of reactive oxygen species from NADH:ubiquinone oxidoreductase to limit induction of interleukin-1 $\beta$ (IL-1 $\beta$ ) and boosts interleukin-10 (IL-10) in lipopolysaccharide (LPS)-activated macrophages. J. Biol. Chem. 290, 20348-20359. doi: 10.1074/jbc.M115.662114

Klionsky, D. J., Abeliovich, H., Agostinis, P., Agrawal, D. K., Aliev, G., Askew, D. S., et al. (2008). Guidelines for the use and interpretation of assays for monitoring autophagy in higher eukaryotes. Autophagy 16, 151-175. doi: 10.4161/auto.5338

Knapowski, J., Wieczorowska-Tobis, K., and Witowski, J. (2002). Pathophysiology of ageing. J. Physiol. Pharamcol. 53, 135-146.

Kofman, A. E., McGraw, M. R., and Payne, C. J. (2012). Rapamycin increases oxidative stress response gene expression in adult stem cells. Aging 4, 279-289. doi: 10.18632/aging.100451

Kong, Y., Cui, H., Ramkumar, C., and Zhang, H. (2011). Regulation of senescence in cancer and aging. J. Aging Res. 2011:963172. doi: 10.4061/2011/963172

Kops, G. J. L., Dansen, T. B., Polderman, P. E., Saarloos, I., Wirtz, K. W. A., Coffer, P. J., et al. (2002). Forkhead transcription factor FOXO3a protects quiescent cells from oxidative stress. Nature 419, 316-321. doi: 10.1038/nature01036

Kriete, A., Mayo, K. L., Yalamanchili, N., Beggs, W., Bender, P., Kari, C., et al. (2008). Cell autonomous expression of inflammatory genes in biologically aged fibroblasts associated with elevated NF-kappaB activity. Immun. Ageing 5:5. doi: 10.1186/1742-4933-5-5

Krokowski, D., Han, J., Saikia, M., Majumder, M., Yuan, C. L., Guan, B. J., et al. (2013). A self-defeating anabolic program leads to beta-cell apoptosis in endoplasmic reticulum stress-induced diabetes via regulation of amino acid flux. J. Biol. Chem. 288, 17202-17213. doi: 10.1074/jbc.M113.466920

Kubben, N., Adriaens, M., Meuleman, W., Voncken, J. W., van Steensel, B., and Misteli, T. (2012). Mapping of lamin A- and progerin-interacting genome regions. Chromosoma 121, 447-464. doi: 10.1007/s00412-012-0376-7

Laberge, R. M., Sun, Y., Orjalo, A. V., Patil, C. K., Freund, A., Zhou, L., et al. (2015). MTOR regulates the pro-tumorigenic senescence-associated secretory phenotype by promoting IL1A translation. Nat. Cell Biol. 17, 1049-1061. doi: $10.1038 / \mathrm{ncb} 3195$

Lan, F., Cacicedo, J. M., Ruderman, N., and Ido, Y. (2008). SIRT1 modulation of the acetylation status, cytosolic localization, and activity of LKB1. Possible role in AMP-activated protein kinase activation. J. Biol. Chem. 283, 27628-27635. doi: 10.1074/jbc.M805711200

Landau, G., Ran, A., Bercovich, Z., Feldmesser, E., Horn-Saban, S., Korkotian, E., et al. (2012). Expression profiling and biochemical analysis suggest stress response as a potential mechanism inhibiting proliferation of polyaminedepleted cells. J. Biol. Chem. 287, 35825-35837. doi: 10.1074/jbc.M112.381335

Laplante, M., and Sabatini, D. M. (2013). Regulation of mTORC1 and its impact on gene expression at a glance. J. Cell Sci. 126(Pt 8), 1713-1719. doi: $10.1242 /$ jcs. 125773

Lau, A. W., Liu, P., Inuzuka, H., and Gao, D. (2014). SIRT1 phosphorylation by AMP-activated protein kinase regulates p53 acetylation. Am. J. Cancer Res. 4, 245-255.

Le Corre, L., Chalabi, N., Delort, L., Bignon, Y. J., and Bernard-Gallon, D. J. (2006). Differential expression of genes induced by resveratrol in human breast cancer cell lines. Nutr. Cancer 56, 193-203. doi: 10.1207/s15327914nc5602_10 
Lee, C., and Longo, V. (2016). Dietary restriction with and without caloric restriction for healthy aging [version 1; referees: 3 approved]. F1000Research 5:117. doi: $10.12688 /$ f1000research.7136.1

Lee, C., and Longo, V. D. (2011). Fasting vs dietary restriction in cellular protection and cancer treatment: from model organisms to patients. Oncogene 30, 3305-3316. doi: 10.1038/onc.2011.91

Lee, H. J., Jung, H., Kwon, J., Li, H., Lee da, Y., Lim, H. J., et al. (2011). A germacranolide sesquiterpene lactone suppressed inducible nitric oxide synthase by downregulating NF-kappaB activity. Can. J. Physiol. Pharmacol. 89, 232-237. doi: 10.1139/Y11-004

Lee, S. K., Park, M. S., and Nam, M. J. (2008). Aspirin has antitumor effects via expression of calpain gene in cervical cancer cells. J. Oncol. 2008:285374. doi: $10.1155 / 2008 / 285374$

Lee, S., and Min, K. (2013). Caloric restriction and its mimetics. BMB Rep. 46, 181-187. doi: 10.5483/BMBRep.2013.46.4.033

Lee, W. M., Paik, J. S., Cho, W. K., Oh, E. H., Lee, S. B., and Yang, S. W. (2013). Rapamycin enhances TNF-alpha-induced secretion of IL-6 and IL-8 through suppressing PDCD4 degradation in orbital fibroblasts. Curr. Eye Res. 38, 699-706. doi: 10.3109/02713683.2012.750368

Li, Y., Liu, L., Andrews, L. G., and Tollefsbol, T. O. (2009). Genistein depletes telomerase activity through cross-talk between genetic and epigenetic mechanisms. Int. J. Cancer J. Int. Cancer 125, 286-296. doi: 10.1002/ijc.24398

Li, Y., Liu, L., and Tollefsbol, T. O. (2010a). Glucose restriction can extend normal cell lifespan and impair precancerous cell growth through epigenetic control of hTERT and p16 expression. FASEB J. 24, 1442-1453. doi: 10.1096/fj.09-149328

Li, Y., Yuan, Y. Y., Meeran, S. M., and Tollefsbol, T. O. (2010b). Synergistic epigenetic reactivation of estrogen receptor-alpha (ERalpha) by combined green tea polyphenol and histone deacetylase inhibitor in ERalpha-negative breast cancer cells. Mol. Cancer 9:274. doi: 10.1186/1476-4598-9-274

Lim, C. T., Kola, B., and Korbonits, M. (2010). AMPK as a mediator of hormonal signalling. J. Mol. Endocrinol. 44, 87-97. doi: 10.1677/JME-09-0063

Lim, J. H., Lee, Y. M., Chun, Y. S., Chen, J., Kim, J. E., and Park, J. W. (2010). Sirtuin 1 modulates cellular responses to hypoxia by deacetylating hypoxia-inducible factor lalpha. Mol. Cell 38, 864-878. doi: 10.1016/j.molcel.2010.05.023

Longo, V. D. (2009). Linking sirtuins, IGF-I signaling, and starvation. Exp. Gerontol. 44, 70-74. doi: 10.1016/j.exger.2008.06.005

Manna, S. K., Mukhopadhyay, A., and Aggarwal, B. B. (2000). Resveratrol suppresses TNF-induced activation of nuclear transcription factors NF$\mathrm{B}$, activator protein-1, and apoptosis: potential role of reactive oxygen intermediates and lipid peroxidation. J. Immunol. 164, 6509-6519. doi: 10.4049/jimmunol.164.12.6509

Martin-Montalvo, A., Mercken, E. M., Mitchell, S. J., Palacios, H. H., Mote, P. L., Scheibye-Knudsen, M., et al. (2013). Metformin improves healthspan and lifespan in mice. Nat. Commun. 4:2192. doi: 10.1038/ncomms3192

Masri, S., and Sassone-Corsi, P. (2013). The circadian clock: a framework linking metabolism, epigenetics and neuronal function. Nature Rev. Neurosci. 14, 69-75. doi: $10.1038 / \mathrm{nrn} 3393$

Massacesi, C., Di Tomaso, E., Urban, P., Germa, C., Quadt, C., Trandafir, L., et al. (2016). PI3K inhibitors as new cancer therapeutics: implications for clinical trial design. Onco Targets Ther. 9, 203-210. doi: 10.2147/OTT.S89967

Mattison, J. A., Roth, G. S., Beasley, T. M., Tilmont, E. M., Handy, A. M., Herbert, R. L., et al. (2012). Impact of caloric restriction on health and survival in rhesus monkeys from the NIA study. Nature 489, 318-321. doi: 10.1038/ nature11432

McCay, C. M., Crowell, M. F., and Maynard, L. A. (1935). The Effect of retarded growth upon the length of life span and upon the ultimate body size. J. Nutr. 10, 63-79.

Mehta, I. S., Amira, M., Harvey, A. J., and Bridger, J. M. (2010). Rapid chromosome territory relocation by nuclear motor activity in response to serum removal in primary human fibroblasts. Genome Biol. 11:R5. doi: 10.1186/gb-2010-11-1-r5

Mehta, I. S., Eskiw, C. H., Arican, H. D., Kill, I. R., and Bridger, J. M. (2011). Farnesyltransferase inhibitor treatment restores chromosome territory positions and active chromosome dynamics in Hutchinson-Gilford progeria syndrome cells. Genome Biol. 12:R74. doi: 10.1186/gb-2011-12-8-r74

Meydani, S., Das, S., Piper, C., Lewis, M., Dixit, V., Gupta, A., et al. (2014). Effects of prolonged calorie restriction on inflammation and immune function: a randomized controlled trial in non-obese humans. FASEB J. 28(Suppl. 40.4). doi: 10.1096/fj.1530-6860
Miller, R. A., Harrison, D. E., Astle, C. M., Baur, J. A., Boyd, A. R., de Cabo, R., et al. (2011). Rapamycin, but not resveratrol or simvastatin, extends life span of genetically heterogeneous mice. J. Gerontol. A Biol. Sci. Med. Sci. 66, 191-201. doi: 10.1093/gerona/glq178

Miller, R. A., Harrison, D. E., Astle, C. M., Fernandez, E., Flurkey, K., Han, M., et al. (2014). Rapamycin-mediated lifespan increase in mice is dose and sex dependent and metabolically distinct from dietary restriction. Aging Cell 13, 468-477. doi: 10.1111/acel.12194

Minois, N. (2014). Molecular basis of the 'anti-aging' effect of spermidine and other natural polyamines - a mini-review. Gerontology 60, 319-326. doi: $10.1159 / 000356748$

Minois, N., Carmona-Gutierrez, D., and Madeo, F. (2011). Polyamines in aging and disease. Aging 3, 1-17. doi: 10.18632/aging.100361

Miwa, S., Riyahi, K., Partridge, L., and Brand, M. D. (2004). Lack of correlation between mitochondrial reactive oxygen speicies production and life span in Drosophila. Ann. N.Y. Acad. Sci. 1019, 388-391. doi: 10.1196/annals.1297.069

Miyamura, Y., Ohtsu, H., Niwa, O., Kurishita, A., Watanabe, H., Sado, T., et al. (1993). Comparison of the age- and tumor-associated changes in the c-myc gene methylation in mouse liver. Gerontology 39(Suppl. 1), 3-10. doi: $10.1159 / 000213558$

Morselli, E., Marino, G., Bennetzen, M. V., Eisenberg, T., Megalou, E., Schroeder, S., et al. (2011). Spermidine and resveratrol induce autophagy by distinct pathways converging on the acetylproteome. J. Cell Biol. 192, 615-629. doi: 10.1083/jcb.201008167

Mukherjee, P., Abate, L. E., and Seyfried, T. N. (2004). Antiangiogenic and proapoptotic effects of dietary restriction on experimental mouse and human brain tumors. Clin. Cancer Res. 10, 5622-5629. doi: 10.1158/1078-0432.CCR04-0308

Mulrooney, T. J., Marsh, J., Urits, I., Seyfried, T. N., and Mukherjee, P. (2011). Influence of caloric restriction on constitutive expression of NFkappaB in an experimental mouse astrocytoma. PLOS ONE 6:e18085. doi: 10.1371/journal.pone.0018085

Murphy, C. T., and Hu, P. J. (2013). "Insulin/insulin-like growth factor signaling in C. elegans," in WormBook, ed The C. elegans Research Community. doi: 10.1895/wormbook.1.164.1. Available online at: http://www.wormbook.org

Musich, P. R., and Zou, Y. (2011). DNA-damage accumulation and replicative arrest in Hutchinson-Gilford progeria syndrome. Biochem. Soc. Trans. 39, 1764-1769. doi: 10.1042/BST20110687

Narayanan, B. A., Narayanan, N. K., Re, G. G., and Nixon, D. W. (2003). Differential expression of genes induced by resveratrol in LNCaP cells: P53mediated molecular targets. Int. J. Cancer 104, 204-212. doi: 10.1002/ijc. 10932

Nelson, L. E., Valentine, R. J., Cacicedo, J. M., Gauthier, M. S., Ido, Y., and Ruderman, N. B. (2012). A novel inverse relationship between metformintriggered AMPK-SIRT1 signaling and $\mathrm{p} 53$ protein abundance in high glucoseexposed HepG2 cells. Am. J. Physiol. Cell Physiol. 303, C4-C13. doi: 10.1152/ajpcell.00296.2011

Nemoto, A., Fergusson, M. M., and Finkel, T. (2004). Nutrient availability regulates SIRT1 through a forkhead-dependent pathway. Science 306, 2105-2108. doi: 10.1126/science.1101731

Nemoto, S., and Finkel, T. (2002). Redox regulation of forkhead proteins through a p66shc-dependent signaling pathway. Science 295, 2450-2452. doi: 10.1126/science.1069004

Nijland, M. J., Schlabritz-Loutsevitch, N. E., Hubbard, G. B., Nathanielsz, P. W., and Cox, L. A. (2007). Non-human primate fetal kidney transcriptome analysis indicates mammalian target of rapamycin (mTOR) is a central nutrientresponsive pathway. J. Physiol. 579, 643-656. doi: 10.1113/jphysiol.2006. 122101

Niles, R. M., McFarland, M., Weimer, M. B., Redkar, A., Fu, Y.-M., and Meadows, G. G. (2003). Resveratrol is a potent inducer of apoptosis in human melanoma cells. Cancer Lett. 190, 157-163. doi: 10.1016/S0304-3835(02)00676-6

Nishimura, K., Shiina, R., Kashiwagi, K., and Igarashi, K. (2006). Decrease in polyamines with aging and their ingestion from food and drink. J. Biochem. 139, 81-90. doi: $10.1093 / \mathrm{jb} / \mathrm{mvj003}$

Onken, B., and Driscoll, M. (2010). Metformin induces a dietary restrictionlike state and the oxidative stress response to extend $C$. elegans Healthspan via AMPK, LKB1, and SKN-1. PLOS ONE 5:e8758. doi: 10.1371/journal.pone. 0008758 
Opalach, K., Rangaraju, S., Madorsky, I., Leeuwenburgh, C., and Notterpek, L. (2010). Lifelong calorie restriction alleviates age-related oxidative damage in peripheral nerves. Rejuvenation Res. 13, 65-74. doi: 10.1089/rej.2009.0892

Oshida, K., Vasani, N., Thomas, R. S., Applegate, D., Rosen, M., Abbott, B., et al. (2015). Identification of modulators of the nuclear receptor peroxisome proliferator-activated receptor alpha (PPARalpha) in a mouse liver gene expression compendium. PLOS ONE 10:e0112655. doi: 10.1371/journal.pone.0112655

Owen, M. R., Doran, E., and Halestrap, A. P. (2000). Evidence that metformin exerts its anti-diabetic effects through inhibition of complex 1 of the mitochondrial respiratory chain. Biochem. J. 348, 607-614. doi: 10.1042/bj3480607

Pacholec, M., Bleasdale, J. E., Chrunyk, B., Cunningham, D., Flynn, D., Garofalo, R. S., et al. (2010). SRT1720, SRT2183, SRT1460, and resveratrol are not direct activators of SIRT1. J. Biol. Chem. 285, 8340-8351. doi: 10.1074/jbc.M109.088682

Palou, M., Priego, T., Romero, M., Szostaczuk, N., Konieczna, J., Cabrer, C., et al. (2015). Moderate calorie restriction during gestation programs offspring for lower BAT thermogenic capacity driven by thyroid and sympathetic signaling. Int. J. Obes. 39, 339-345. doi: 10.1038/ijo.2014.56

Park, S. K., and Prolla, T. A. (2005). Lessons learned from gene expression profile studies of aging and caloric restriction. Ageing Res. Rev. 4, 55-65. doi: 10.1016/j.arr.2004.09.003

Plank, M., Wuttke, D., van Dam, S., Clarke, S. A., and de Magalhaes, J. P. (2012). A meta-analysis of caloric restriction gene expression profiles to infer common signatures and regulatory mechanisms. Mol. Biosyst. 8, 1339-1349. doi: $10.1039 / \mathrm{c} 2 \mathrm{mb} 05255 \mathrm{e}$

Ponzio, B. F., Carvalho, M. H., Fortes, Z. B., and do Carmo Franco, M. (2012). Implications of maternal nutrient restriction in transgenerational programming of hypertension and endothelial dysfunction across F1-F3 offspring. Life Sci. 90, 571-577. doi: 10.1016/j.lfs.2012.01.017

Powers, R. W. III, Kaeberlein, M., Caldwell, S. D., Kennedy, B. K., and Fields, S. (2006). Extension of chronological life span in yeast by decreased TOR pathway signaling. Genes Dev. 20, 174-184. doi: 10.1101/gad.1381406

Qin, W., Zhao, W., Ho, L., Wang, J., Walsh, K., Gandy, S., et al. (2008). Regulation of forkhead transcription factor FoxO3a contributes to calorie restrictioninduced prevention of Alzheimer's disease-type amyloid neuropathology and spatial memory deterioration. Ann. N.Y. Acad. Sci. 1147, 335-347. doi: 10.1196/annals. 1427.024

Ray, P. D., Huang, B. W., and Tsuji, Y. (2012). Reactive oxygen species (ROS) homeostasis and redox regulation in cellular signaling. Cell. Signal. 24, 981-990. doi: 10.1016/j.cellsig.2012.01.008

Ren, Z., Wang, L., Cui, J., Huoc, Z., Xue, J., Cui, H., et al. (2013). Resveratrol inhibits NF-кB signaling through suppression of p65 and ІкB kinase activties. Pharmazie 68, 689-694.

Renaud, S., and de Lorgeril, M. (1992). Wine, alcohol, platelets, and the French paradox for coronary heart disease. Lancet 339, 1523-1526. doi: 10.1016/01406736(92)91277-F

Richter, J. D., and Sonenberg, N. (2005). Regulation of cap-dependent translation by eIF4E inhibitory proteins Nature 433, 477-480. doi: 10.1038/nature03205

Romier, B., Van De Walle, J., During, A., Larondelle, Y., and Schneider, Y. J. (2008). Modulation of signalling nuclear factor-kappaB activation pathway by polyphenols in human intestinal Caco-2 cells. Br. J. Nutr. 100, 542-551. doi: 10.1017/S0007114508966666

Roosen, J., Engelen, K., Marchal, K., Mathys, J., Griffioen, G., Cameroni, E., et al. (2005). PKA and Sch9 control a molecular switch important for the proper adaptation to nutrient availability. Mol. Microbiol. 55, 862-880. doi: 10.1111/j.1365-2958.2004.04429.x

Saliou, C., Rihn, B., Cillard, J., Okamoto, T., and Packer, L. (1998). Selective Inhibition of NF- $\kappa \mathrm{B}$ activation by the flavonoid hepatoprotector silymarin in HepG2. FEBS Lett. 440, 8-12. doi: 10.1016/S0014-5793(98)01409-4

Santos, R. X., Correia, S. C., Cardoso, S., Carvalho, C., Santos, M. S., and Moreira, P. I. (2011). Effects of rapamycin and TOR on aging and memory: implications for Alzheimer's disease. J. Neurochem. 117, 927-936. doi: 10.1111/j.14714159.2011.07262.x

Sarbassov, D. D., Ali, S. M., Sengupta, S., Sheen, J. H., Hsu, P. P., Bagley, A. F., et al. (2006). Prolonged rapamycin treatment inhibits mTORC2 assembly and Akt/PKB. Mol. Cell 22, 159-168. doi: 10.1016/j.molcel.2006.03.029
Schoenfelder, S., Sexton, T., Chakalova, L., Cope, N. F., Horton, A., Andrews, S., et al. (2010). Preferential associations between co-regulated genes reveal a transcriptional interactome in erythroid cells. Nat. Genet. 42, 53-61. doi: 10.1038/ng.496

Sehgal, S. N., Baker, H., and Vezina, C. (1975). Rapamycin (AY-22,989), a new antifungal antibiotic. II fermentation, isolation and characterization. J. Antibiot. $28,727-732$

Shapira, M., Kakiashvili, E., Rosenberg, T., and Hershko, D. D. (2006). The mTOR inhibitor rapamycin down-regulates the expression of the ubiquitin ligase subunit Skp2 in breast cancer cells. Breast Cancer Res. 8, R46. doi: $10.1186 /$ bcr 1533

Shimokawa, I., Komatsu, T., Hayashi, N., Kim, S., Kawata, T., Park, S., et al. (2015). The life-extending effect of dietary restriction requires Foxo3 in mice. Aging Cell 14, 707-709. doi: 10.1111/acel.12340

Shin, Y. J., Cho, D. Y., Chung, T. Y., Han, S. B., Hyon, J. Y., and Wee, W. R. (2011). Rapamycin reduces reactive oxygen species in cultured human corneal endothelial cells. Curr. Eye Res. 36, 1116-1122. doi: $10.3109 / 02713683.2011 .614372$

Sidorova, J. M. (2008). Roles of the Werner syndrome RecQ helicase in DNA replication. DNA Repair 7, 1776-1786. doi: 10.1016/j.dnarep.2008.07.017

Sinclair, D. A. (2005). Toward a unified theory of caloric restriction and longevity regulation. Mech. Ageing Dev. 126, 987-1002. doi: 10.1016/j.mad.2005. 03.019

Singh, B., N., Shankar, S., and Srivastava, R. K. (2011). Green tea catechin, epigallocatechin-3-gallate (EGCG): mechanisms, perspectives and clinical applications. Biochem. Pharmacol. 82, 1807-1821. doi: 10.1016/j.bcp.2011.07.093

Singh, H., Tahir, T. A., Alawo, D. O., Issa, E., and Brindle, N. P. (2011). Molecular control of angiopoietin signalling. Biochem. Soc. Trans. 39, 1592-1596. doi: 10.1042/BST20110699

Singh, V. P., Bali, A., Singh, N., and Jaggi, A. S. (2014). Advanced glycation end products and diabetic complications. Korean J. Physiol. Pharmacol. 18, 1-14. doi: 10.4196/kjpp.2014.18.1.1

Singhal, R. P., Mays-Hoopes, L. L., and Eichhorn, G. L. (1987). DNA methylation in aging of mice. Mech. Ageing Dev. 41, 199-210. doi: 10.1016/00476374(87)90040-6

Slack, C., Foley, A., and Partridge, L. (2012). Activation of AMPK by the putative dietary restriction mimetic metformin is insufficient to extend lifespan in Drosophila. PLoS ONE 7:e47699. doi: 10.1371/journal.pone.0047699

Smith, D. L. Jr., Elam, C. F. Jr., Mattison, J. A., Lane, M. A., Roth, G. S., Ingram, D. K., et al. (2010). Metformin supplementation and life span in Fischer-344 rats J. Gerontol. A Biol. Sci. Med. Sci. 65, 468-474. doi: 10.1093/gerona/glq033

Spaulding, C. C., Walford, R. L., and Effros, R. B. (1997). Calorie restriction inhibits the age-related dysregulation of the cytokines TNF-a and IL-6 in C3B10RF1 mice. Mech. Ageing Dev. 93, 87-94. doi: 10.1016/S0047-6374(96)01824-6

Stein, S., and Matter, C. M. (2011). Protective roles of SIRT1 in atherosclerosis. Cell Cycle 10, 640-647. doi: 10.4161/cc.10.4.14863

Stervbo, U., Vang, O., and Bonnesen, C. (2007). A review of the content of the putative chemopreventive phytoalexin resveratrol in red wine. Food Chem. 101, 449-457. doi: 10.1016/j.foodchem.2006.01.047

Su, X., Yu, Y., Zhong, Y., Giannopoulou, E. G., Hu, X., Liu, H., et al. (2015). Interferon-gamma regulates cellular metabolism and mRNA translation to potentiate macrophage activation. Nat. Immunol. 16, 838-849. doi: 10.1038/ni.3205

Suzuki, M., Endo, M., Shinohara, F., Echigo, S., and Rikiishi, H. (2011). Rapamycin suppresses ROS-dependent apoptosis caused by selenomethionine in A549 lung carcinoma cells. Cancer Chemother. Pharmacol. 67, 1129-1136. doi: 10.1007/s00280-010-1417-7

Swindell, W. R. (2009). Genes and gene expression modules associated with caloric restriction and aging in the laboratory mouse. BMC Genomics 10:585. doi: 10.1186/1471-2164-10-585

Swinnen, E., Wanke, V., Roosen, J., Smets, B., Dubouloz, F., Pedruzzi, I., et al. (2006). Rim15 and the crossroads of nutrient signalling pathways in Saccharomyces cerevisiae. Cell Div. 1:3. doi: 10.1186/1747-1028-1-3

Takayama, H., Misu, H., Iwama, H., Chikamoto, K., Saito, Y., Murao, K., et al. (2014). Metformin suppresses expression of the selenoprotein $\mathrm{P}$ gene via an AMP-activated kinase (AMPK)/FoxO3a pathway in H4IIEC3 hepatocytes. J. Biol. Chem. 289, 335-345. doi: 10.1074/jbc.M113.479386 
Takeda-Watanabe, A., Kitada, M., Kanasaki, K., and Koya, D. (2012). SIRT1 inactivation induces inflammation through the dysregulation of autophagy in human THP-1 cells. Biochem. Biophys. Res. Commun. 427, 191-196. doi: 10.1016/j.bbrc.2012.09.042

Tolhuis, B., Palstra, R. J., Splinter, E., Grosveld, F., and de Laat, W. (2002). Looping and Interaction between hypersensitive sites in the Active $\beta$-globin Locus. Mol. Cell. 10, 1453-1465. doi: 10.1016/S1097-2765(02)00781-5

Torres-Perez, M., Tellez-Ballesteros, R. I., Ortiz-Lopez, L., Ichwan, M., VegaRivera, N. M., Castro-Garcia, M., et al. (2015). Resveratrol enhances neuroplastic changes, including hippocampal neurogenesis, and memory in Balb/C mice at six months of age. PLoS ONE 10:e0145687. doi: 10.1371/journal.pone.0145687

Um, J. H., Kim, S. J., Kim, D. W., Ha, M. Y., Jang, J. H., Kim, D. W., et al. (2003). Tissue-specific changes of DNA repair protein $\mathrm{Ku}$ and $\mathrm{mtHSP70}$ in aging rats and their retardation by caloric restriction. Mech. Ageing Dev. 124, 967-975. doi: 10.1016/S0047-6374(03)00169-6

Uribarri, J., del Castillo, M. D., de la Maza, M. P., Filip, R., Gugliucci, A., LuevanoContreras, C., et al. (2015). Dietary advanced glycation end products and their role in health and disease. Adv. Nutr. 6, 461-473. doi: 10.3945/an.115.008433

Valenzano, D. R., Terzibasi, E., Genade, T., Cattaneo, A., Domenici, L., and Cellerino, A. (2006). Resveratrol prolongs lifespan and retards the onset of age-related markers in a short-lived vertebrate. Curr. Biol. 16, 296-300. doi: 10.1016/j.cub.2005.12.038

van der Horst, A., Tertoolen, L. G., de Vries-Smits, L. M., Frye, R. A., Medema, R. H., and Burgering, B. M. (2004). FOXO4 is acetylated upon peroxide stress and deacetylated by the longevity protein hSir2(SIRT1). J. Biol. Chem. 279, 28873-28879. doi: 10.1074/jbc.M401138200

Vaquero, A., Scher, M., Erdjument-Bromage, H., Tempst, P., Serrano, L., and Reinberg, D. (2007). SIRT1 regulates the histone methyl-transferase SUV39H1 during heterochromatin formation. Nature 450, 440-444. doi: 10.1038 /nature 06268

Vaquero, A., Scher, M., Lee, D., Erdjument-Bromage, H., Tempst, P., and Reinberg, D. (2004). Human SirT1 interacts with histone H1 and promotes formation of facultative heterochromatin. Mol. Cell 16, 93-105. doi: 10.1016/j.molcel.2004.08.031

Verges, B., and Cariou, B. (2015). mTOR inhibitors and diabetes. Diabetes Res. Clin. Pract. 110, 101-108. doi: 10.1016/j.diabres.2015.09.014

Vidan, S., and Mitchell, A. P. (1997). Stimulation of yeast meiotic gene expression by the glucose-repressible protein kinase rim15p. Mol. Cell Biol. 17, 2688-2697. doi: 10.1128/MCB.17.5.2688

Vivo, M., Vera, N., Cortes, R., Mengod, G., Camon, L., and Martinez, E. (2001). Polyamines in the basal ganglia of human brain. Influence of aging and degenerative movement disorders. Neurosci. Lett. 294, 107-111. doi: 10.1016/S0304-3940(01)01776-1

Wang, F., Chan, C. H., Chen, K., Guan, X., Lin, H. K., and Tong, Q. (2012). Deacetylation of FOXO3 by SIRT1 or SIRT2 leads to Skp2-mediated FOXO3 ubiquitination and degradation. Oncogene 31, 1546-1557. doi: 10.1038/onc.2011.347

Wang, J., Liu, Y. T., Xiao, L., Zhu, L., Wang, Q., and Yan, T. (2014). Antiinflammatory effects of apigenin in lipopolysaccharide-induced inflammatory in acute lung injury by suppressing COX-2 and NF-kB pathway. Inflammation 37, 2085-2090. doi: 10.1007/s10753-014-9942-x

Wang, T. T., Hudson, T. S., Wang, T. C., Remsberg, C. M., Davies, N. M., Takahashi, Y., et al. (2008). Differential effects of resveratrol on androgenresponsive $\mathrm{LNCaP}$ human prostate cancer cells in vitro and in vivo. Carcinogenesis 29, 2001-2010. doi: 10.1093/carcin/bgn131

Wei, M., Fabrizio, P., Hu, J., Ge, H., Cheng, C., Li, L., et al. (2008). Life span extension by calorie restriction depends on Rim15 and transcription factors downstream of Ras/PKA, Tor, and Sch9. PLoS Genet. 4:e13. doi: 10.1371/journal.pgen.0040013

Weindruch, R., Kayo, T., Lee, C.-K., and Prolla, T. A. (2001). Microarray profiling of gene expression in aging and its alteration by caloric restriction in mice. J. Nutr. 131, 918S-923S.

Weindruch, R., Walford, R. L., Fligiel, S., and Guthrie, D. (1986). The retardation of aging in mice by dietary restriction: longevity, cancer, immunity and lifetime energy intake. J. Nutr. 155, 641-654.
Whitaker, R., Pilar Gil, M., Ding, F., Tatar, M., Helfand, S. L., and Neretti, N. (2014). Dietary switch reveals fast coordinated gene expression changes in Drosophila melanogaster. Aging 6, 355-368. doi: 10.18632/aging. 100662

Witters, L. A. (2001). The blooming of the French lilac. J. Clin. Invest. 108, 1105-1107. doi: 10.1172/JCI14178

Wood, J. G., Rogina, B., Lavu, S., Howitz, K., Helfand, S. L., Tatar, M., et al. (2004). Sirtuin activators mimic caloric restriction and delay ageing in metazoans. Lett. Nat. 430, 686-689. doi: 10.1038/nature02789

Xia, N., Strand, S., Schlufter, F., Siuda, D., Reifenberg, G., Kleinert, H., et al. (2013). Role of SIRT1 and FOXO factors in eNOS transcriptional activation by resveratrol. Nitric Oxide 32, 29-35. doi: 10.1016/j.niox.2013.04.001

Xu, W., Deng, Y. Y., Yang, L., Zhao, S., Liu, J., Zhao, Z., et al. (2015). Metformin ameliorates the proinflammatory state in patients with carotid artery atherosclerosis through sirtuin 1 induction. Transl. Res. 166, 451-458. doi: 10.1016/j.trsl.2015.06.002

Yang, H., Rudge, D. G., Koos, J. D., Vaidialingam, B., Yang, H. J., and Pavletich, N. P. (2013). mTOR kinase structure, mechanism and regulation. Nature 497, 217-223. doi: 10.1038/nature12122

Yang, S. H., Kim, J. S., Oh, T. J., Kim, M. S., Lee, S. W., Woo, S. K., et al. (2003). Genome-scale analysis of resveratrol-induced gene expression profile in human ovarian cancer cells using a cDNA microarray. J. Oncol. 22, 741-750. doi: 10.3892/ijo.22.4.741

Yao, Y., Li, H., Gu, Y., Davidson, N. E., and Zhou, Q. (2010). Inhibition of SIRT1 deacetylase suppresses estrogen receptor signaling. Carcinogenesis 31, 382-387. doi: 10.1093/carcin/bgp308

Young, L. F., Hantz, H. L., and Martin, K. R. (2005). Resveratrol modulates gene expression associated with apoptosis, proliferation and cell cycle in cells with mutated human c-Ha-Ras, but does not alter c-Ha-Ras mRNA or protein expression. J. Nutr. Biochem. 16, 663-674. doi: 10.1016/j.jnutbio.2005. 03.004

Zhang, J., and Liu, F. (2014). Tissue-specific insulin signaling in the regulation of metabolism and aging. IUBMB Life 66, 485-495. doi: 10.1002/iub.1293

Zhang, S., Cai, G., Fu, B., Feng, Z., Ding, R., Bai, X., et al. (2012). SIRT1 is required for the effects of rapamycin on high glucose-inducing mesangial cells senescence. Mech. Ageing Dev. 133, 387-400. doi: 10.1016/j.mad.2012. 04.005

Zhang, Y., Bokov, A., Gelfond, J., Soto, V., Ikeno, Y., Hubbard, G., et al. (2014). Rapamycin extends life and health in C57BL/6 mice. J. Gerontol. A Biol. Sci. Med. Sci. 69, 119-130. doi: 10.1093/gerona/glt056

Zhao, J., Benakanakere, M. R., Hosur, K. B., Galicia, J. C., Martin, M., and Kinane, D. F. (2010). Mammalian target of rapamycin (mTOR) regulates TLR3 induced cytokines in human oral keratinocytes. Mol. Immunol. 48, 294-304. doi: 10.1016/j.molimm.2010.07.014

Zhou, G., Myers, R., Li, Y., Chen, Y., Shen, X., Fenyk-Melody, J., et al. (2001). Role of AMP-activated protein kinase in mechanism of metformin action. J. Clin. Invest. 108, 1167-1174. doi: 10.1172/JCI13505

Zhou, H. Y., Katsman, Y., Dhaliwal, N. K., Davidson, S., Macpherson, N. N., Sakthidevi, M., et al. (2014). A Sox2 distal enhancer cluster regulates embryonic stem cell differentiation potential. Genes Dev. 28, 2699-2711. doi: 10.1101/gad.248526.114

Zinke, I., Schutz, C. S., Katzenburger, J. D., Bauer, M., and Pankratz, M. J. (2002). Nutrient control if gene expression in Drosophila: microarray analysis of starvation and sugar-dependent response. EMBO J. 21, 6162-6173. doi: 10.1093/emboj/cdf600

Conflict of Interest Statement: The authors declare that the research was conducted in the absence of any commercial or financial relationships that could be construed as a potential conflict of interest.

Copyright (c) 2016 Gillespie, Pickering and Eskiw. This is an open-access article distributed under the terms of the Creative Commons Attribution License (CC BY). The use, distribution or reproduction in other forums is permitted, provided the original author(s) or licensor are credited and that the original publication in this journal is cited, in accordance with accepted academic practice. No use, distribution or reproduction is permitted which does not comply with these terms. 